\title{
مواجهة جائحة فيروس كورونا المستجد (كوفيد-19) في مصر: التداعيات والسياسات فيروسات
}

\section{The COVID-19 Pandemic in Egypt: Repercussions and Policies}

يعرض هذا التقرير استجابة الحكومة المصرية لجائحة فيروس كورونا المستجد (كوفيد-19)، ويقف على

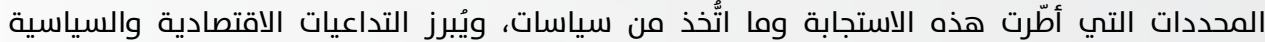

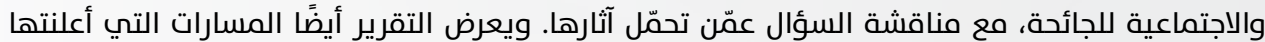

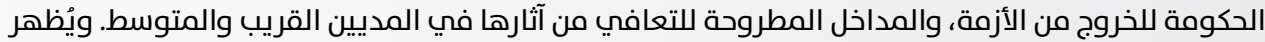

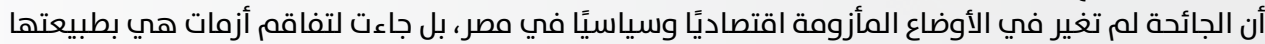

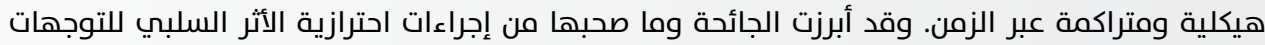

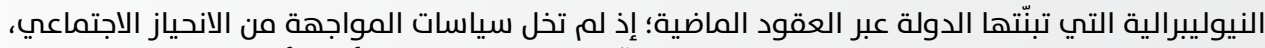

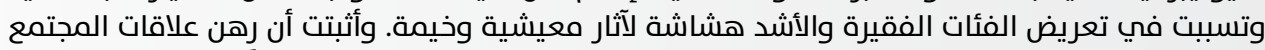

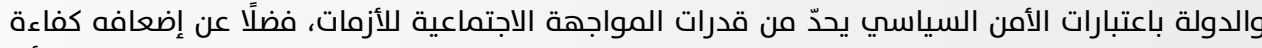

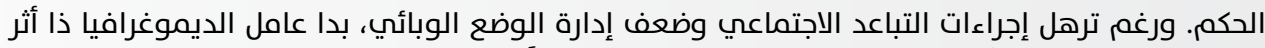

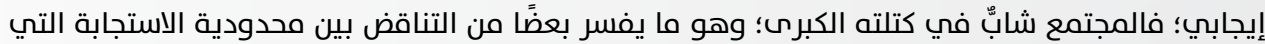

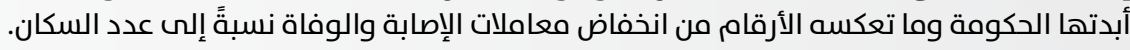

كلمات مفتاحية: فيروس كورونا المستجد (كوفيد-19)، الحكومة المصرية، السلطوية، تداعيات الجائحة، سياسات الطوارئ، الفقر، السياسات النيوليبرالية، الديموغرافيا.

This report investigates the Egyptian government's response to the Covid-19 pandemic, highlighting the economic and socio-political repercussions of this pandemic, and discusses who bore the brunt of the pandemic's impact. It also presents the government's various crisis management strategies, as well as the approaches proposed to recover in the short- and medium-term. The report demonstrates that the pandemic did not mark the beginning of an economic and political crisis in Egypt, but rather exacerbated long-existing structural crises. The pandemic and its accompanying precautionary measures have highlighted the negative impact of neoliberal approaches the state has adopted in the past decades. Neoliberal policies were not without social bias and exposed the poor and most vulnerable groups to disastrous living conditions. The pandemic has proven that state and societal dependence on political security considerations limits crisis management capacities, in addition to weakening governance. Despite the extreme inadequacy of social distancing measures and epidemiological mismanagement, Egypt's relatively young population seems to have reduced the impact of the pandemic, which may explain the contradiction between the government's limited response and low incidence and death rates.

Keywords: Covid-19, Egyptian Government, Authoritarianism, Pandemic Repercussions, Emergency Policies, Poverty, Neoliberal Policies, Demography. 
بالتوازي مع عودة موجة ثانية من الإصابة بفيروس كورونا المستجد (كوفيد-19)، ثار جدلٌ حادّ مجددًا بين الحكومة وقطاع من المعارضة والعاملين في الخدمات الصحية، حول الوضع الوبائي في مصر. وانتقل الجدل إلى مستوى دولي، ليضم منظمة الصحة العالية ذاتها التي شكك مسؤولوها في شفافية وزارة الصحة المصرية زاعمين أنها تنتهج

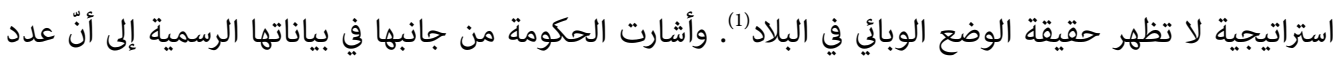

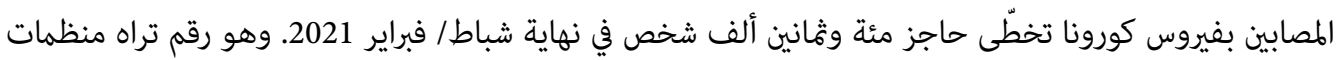
متخصصة محلية ودولية منخفضًا نسبيًا بالنسبة إلى عدد السكان (2). وتردد الحكومة أن الإصابات القليلة قد أثبتت خطأ التوقعات، التي ثارت منذ أن وصلت الجائحة إلى البلاد، بأن تكون مصر إحدى أكثر البؤر الصعبة على المستوى

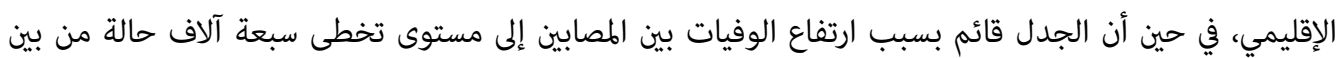
هذه الإصابات المعلنة، أي بنسبة 6 في المئة، وهي النسبة الأعلى بين دول المنطقة (3). وفي ضوء ما يبينه منحنى الإصابات من ذروة جديدة للجائحة، قد تكون أشد وطأة من سابقتها، فإن المخاوف تتجدد

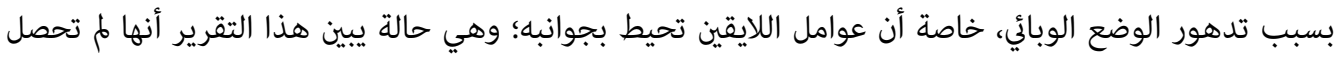

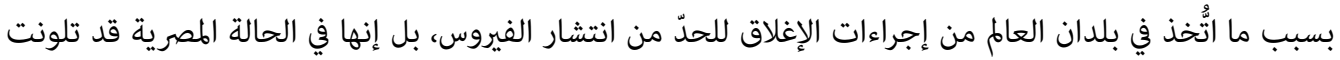
بعوامل سياسية واقتصادية، يلخصها عاملان: عامل الانحياز الاجتماعي في صنع السياسات العامة القائم بسبب النموذج النيوليبرالي المفروض في مصر، وعامل استمرار الأزمة السياسية التي تكتنف نظام الحكم منذ عام 2013.

ولفحص أثر هذين العاملين، يسعى التقرير إلى دراسة استجابة الحكومة وما اتُخذ من سياسات في مواجهة جائحة

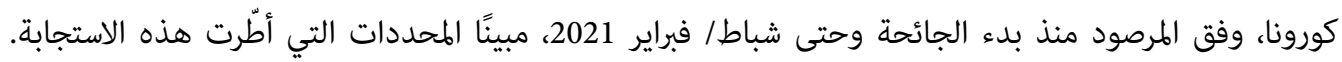
ويحاول أيضًا بيان خصائص الاستجابة الحكومية وبالخصوص تداعياتها الاقتصادية والسياسية - الاجتماعية، وصولًا إلى مناقشة السؤال عمّن تحمّل آثار الجائحة. ويتطرق إلى المسارات المعلنة للخروج من الأزمة، مع بيان المداخل المطروحة للتعافي من آثارها في المديين القريب والمتوسط.

1 البلاد 1 ركز نقد المنظمة على أن الإصابات بمرض جائحة كورونا المستجد (كوفيد-19)، التي تسجلها وزارة الصحة المصرية، لا تعكس حقيقة حجم تفشيه

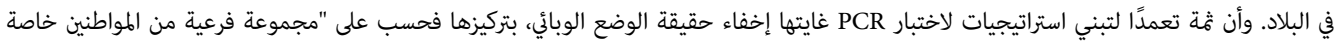

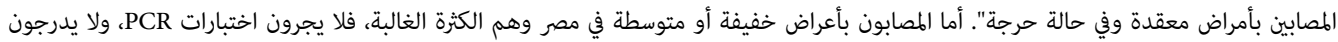

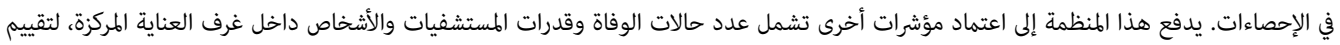

كفاءة الاستجابة للتصدي للجائحة. ينظر:

"Who Official Doubts Egypt's Statistics for Coronavirus Infections," Egypt Independent, 9/12/2020, accessed on 22/2/2021, at: http://bit.ly/3kevhOo

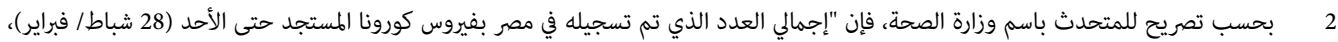

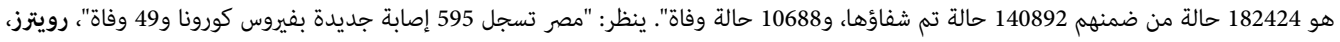

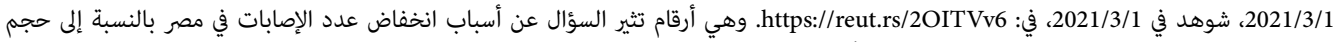

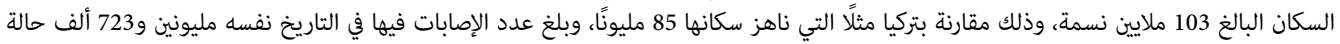

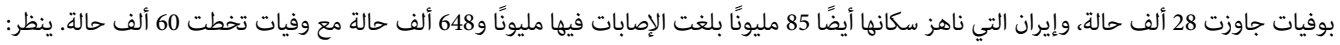
"Reported Cases and Deaths by Country or Territory," Worldometer, 28/2/2021, accessed on 28/2/2021, at: https://bit.ly/310hPy9 3 


\section{أولًا: سياسات الاستجابة للجائحة}

مع وصول جائحة كورونا، غلب التردد العديد من تحركات الحكومة إزاء المطلوب فعله. وبالرغم من أنه حال لا

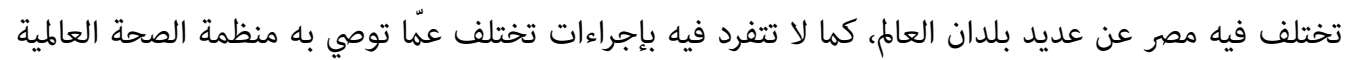
الدول جميعًا، فإن الحكومة، عند شروعها في فرض إجراءات احترازية على أكثر من مستوى، قد عمدت إلى إلى معالجة

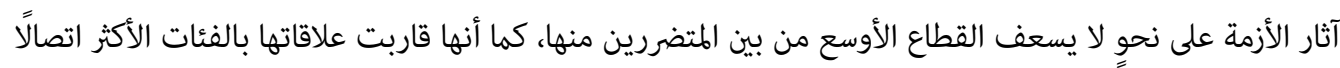
بمواجهة الجائحة من باب الأمن السياسي التقليدي، الذي تسيَّد علاقات المجتمع والدولة. نبين في هذا القسم كيف لماتف طُبقت، منذ آذار/ مارس 2020، حزمتان من القرارات العاجلة، أصدرتهما رئاسة الحكومة والوزارات المعنية: شملت

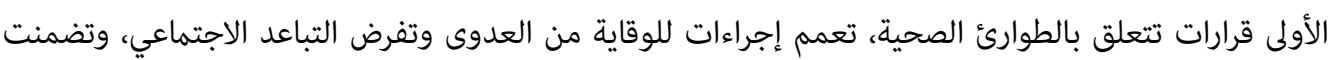

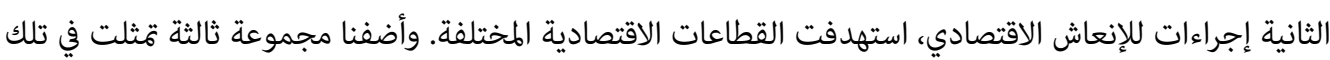
السياسات الأمنية المدفوعة بغايات سياسية، والتي تؤثر اجتماعيًا في قدرات المجتمع على مواجهة الأنية الأزمة.

\section{1. الاستجابة الصحية: إجراءات الطوارئ وما يعترض تطبيقها من معوقات هيكلية}

على إثر الإعلان عن أول حالة للإصابة في البلاد في شباط/ فبراير 2020(4)، تبنت وزارة الصحة والسكان المصرية جملة من إجراءات وقائية كانت قد أوصت بها منظمة الصحة العالمية، وأعلنت الالتزام بتنفيذها في مؤسساتها الصحية،

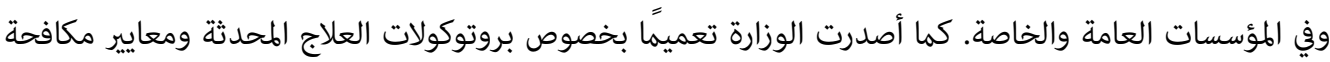
العدوى التي توصي بها المنظمة. وأكدت الوزارة التزامها بالتنسيق مع المكتب الإقليمي للمنظمة في القاهرة لتبادل

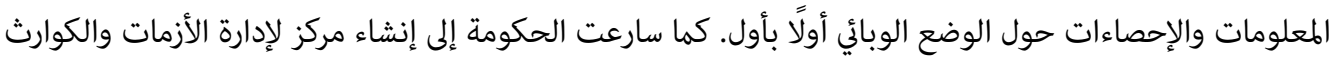

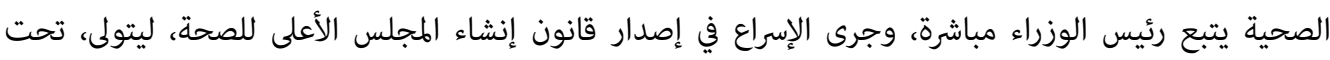

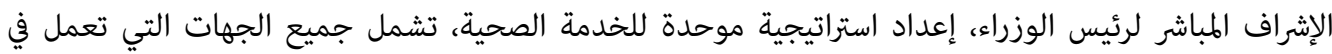
المنظومة الصحية، ووضع التنظيم الملائم لتشغيل المستشفيات الحكومية والخاصة (5).

بعد فترة قصيرة من الإغلاق شبه التام، طرحت الحكومة في أيار/مايو 2020 خطة للتعايش مع الأزمة على مدى

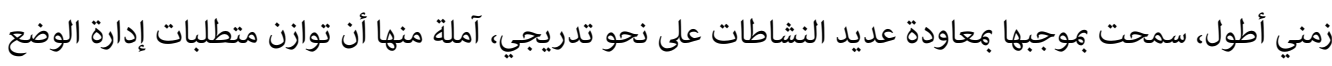

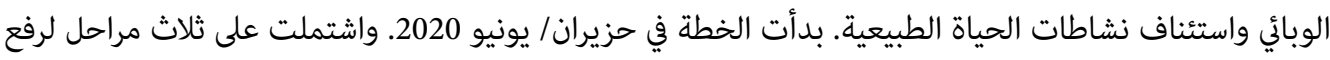

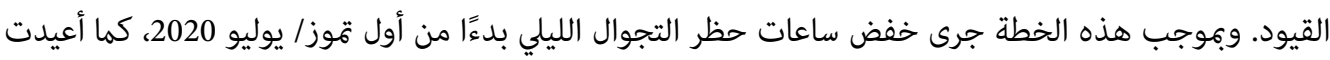

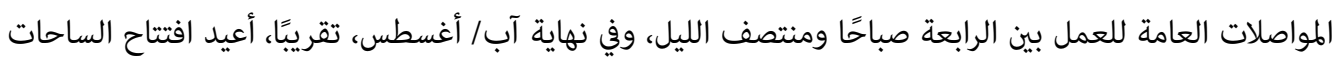
العامة والحدائق للعموم، بنصف سعتها، وسمح للمطاعم بأن تستأنف نشاطها في حدود ربع سعتها، وتم السماح

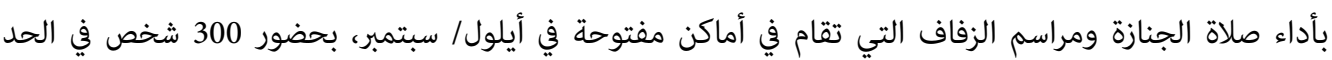
الأقصى. كما استؤنف تصدير الإمدادات الطبية، بعد توقف مؤقت منذ آذار/ مارس 2020.

4 " 4 "فيروس كورونا: اكتشاف أول حالة لمصاب بالفيروس في مصر والتي تعود لشخص 'أجنبي"'، بي بي سي عربي، 2020/2/14، شوهد في 2020/12/18، في: https://bbc.in/3rxpvdy

5 تمت عرقلة المشروع قبل وصول الجائحة إثر خلافات داخل الحكومة. ينظر: "الحكومة: إنشاء مجلس أعلى للصحة لدعم وتعزيز القطاع"، اليوم السابع،

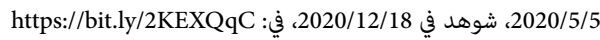


على مستوى الجاهزية الصحية، تطور الوضع في الفترة آذار/ مارس - كانون الأول/ ديسمبر 2020 تطورًا ملحوظًا؛ فقد خصصت الوزارة مع بدء انتشار الجائحة 19 مستشفى للعزل، وصلت في نهاية عام 2020 إلى 101 مستشفى. كما زاد عدد المستشفيات التي تستقبل الحالات المصابة بكورونا من 100 مستشفى إلى 363 مستشفى، وبلغت التهاء طاقة الاستقبال 34275 سريرًا، من ضمنها 4584 سريرًا للرعاية المركزة، و2383 سريرًا للتنفس الصناعي. وجرى توفير ماتير

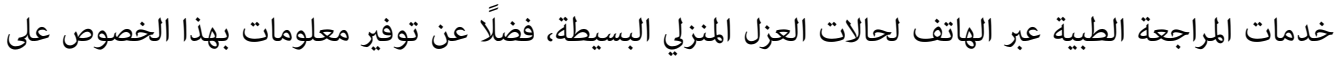
الموقع الإلكتروني الخاص بالوزارة(6). كما أعلنت الوزارة في بدايات عام 2021 عن مبادرة تحمل اسم رئيس الجمهورية

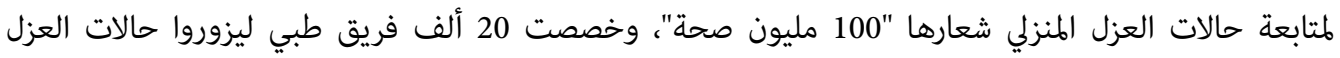
المنزلي لمصابي فيروس كورونا، مزودين بأجهزة "تابلت" لتسجيل البيانات الخاصة بالحالات على التهات النظام الإلكتروني، وأجهزة قياس نسبة الأكسجين، وأجهزة قياس درجة الحرارة، مع اتخاذ الإجراءات الاحترازية والوقاية للفيروس وفقات الونًا

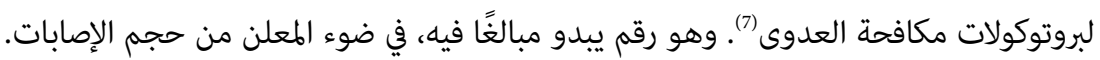
إجمالًا، يمكن القول إنه في بداية الأزمة قد جرى تنفيذ قرارات الطوارئ الطبية وما رافقها من إجراءات احترازية على نحوٍ معقول، معته بدا متناسبًا مع وضعية منظومة الصحة في مصر، لكن الأمور تداعت لمنحى سلبي، بسبب تعجيل الحكومة رفع حظر التجوال

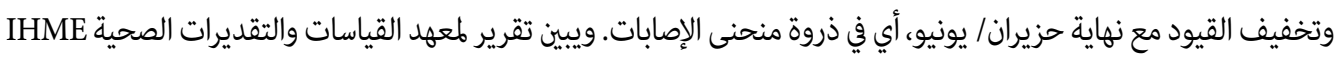

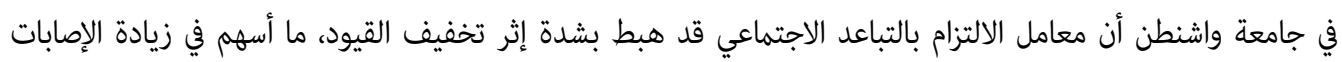

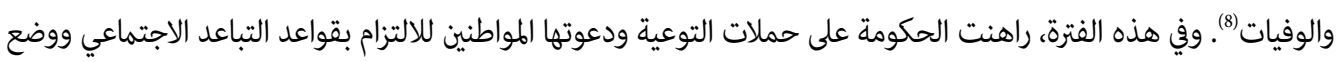

الكمامات. لكنها لم تبذل في المقابل جهدًا حقيقيًا في مجال التشديد الرقابي، فبدت إجراءات التباعد الاجتماعي غير ملموسة.

قد يجد هذا الوضع بعضًا من مبرراته في سياق اجتماعي يسوده انخفاض مستويات الوعي الصحي، واشتداد الضغوط المعيشية على الفقراء، على نحو قد يدفعهم إلى إيثار الخروج للعمل رغم المخاطر، في أماكن تحكمها طبائع الكثافة

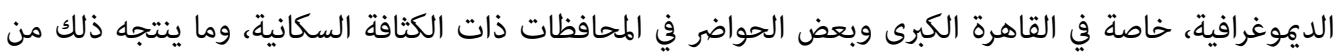

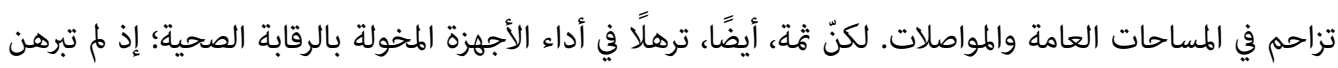
على قدرتها على فرض إجراءات التباعد في المباني والمساحات العامة.

ويثير ضعف الأداء الرقابي من جهة الحكومة الخشية مجددًا في ضوء عودة منحنى الإصابات إلى الصعود منذ تشرين

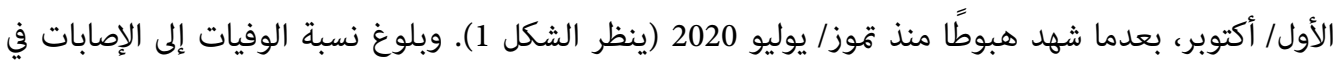

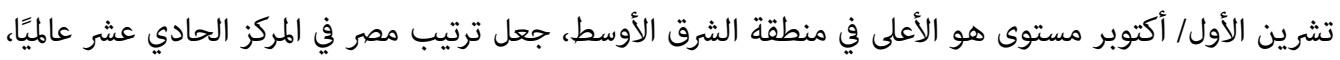
فتعالت التحذيرات من تضاعف عدد الوفيات مع حلول الشتاء؛ وبحسب ما يشير إليه تقرير أعدّه معهد القياسات

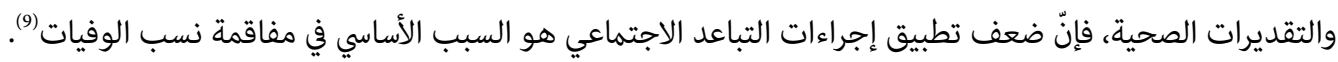

6 من تصريحات للوزيرة في مؤتمر صحفي عقدته في 2020/12/23 بأكاديمية الأميرة فاطمة للتعليم الطبي المهني. ينظر: مريم الخطري، "في كل محافظة..

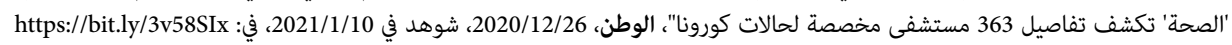
7 الوزيرة الصحة: انطلاق مبادرة رئيس الجمهورية لمتابعة حالات العزل المنزلي لمرضى فيروس كورونا المستجد"، الهيئة العامة للاستعلامات،

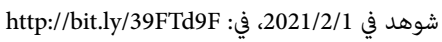

8 "Egypt: Model Update," The Institute for Health Metrics and Evaluation, 29/10/2020, 5/12/2020, at: https://bit.ly/2OCfUUf 9 Ibid. 
ومن المؤشرات التي تظهر ذلك مؤشر تنقّل المواطنين الذي شهد ارتفاعًا في الحركة رافق قرارات التخفيف من قيود الحركة والإغلاق. وأظهرت خرائط مراقبة حركة الهواتف الذكية أنّ معدل الحركة في تشرين الأول/ أكتوبر كان أقل بنحو 10 في المئة فقط مما كان قبل الجائحة، أي عن خط الأساس المحدد بكانون الثاني/ يناير 2020 (10). وقد عزا التقرير رفع نسب الوفيات إلى ارتفاع الحركة مع انخفاض استخدام المواطنين الكمامات الواقية. وتوقّع التقرير في حال استمر هذا الوضع تضاعف حجم الوفيات (المعلنة رسميًا) بحلول شباط/ فبراير 2021، وتخطيها حاجز 11400 وفاة (وصلت بالفعل بحسب البيان المعلن من الوزارة في نهاية شباط/ فبراير 10688 وفاة) وهو الوقت الذي قد

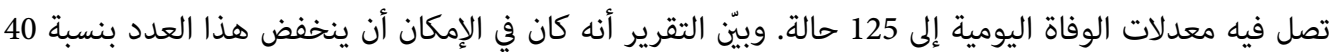
في المئة تقريبًا، إذا ما سارعت الحكومة في تشديد رقابتها والعمل الجدي على فرض وضع الأقنعة في الأماكن العامة، وهو ما مل يحدث حتى نهاية شباط/ فبراير 2021

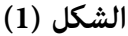

\section{عودة منحنى الإصابات بفيروس كورونا المستجد إلى الصعود}

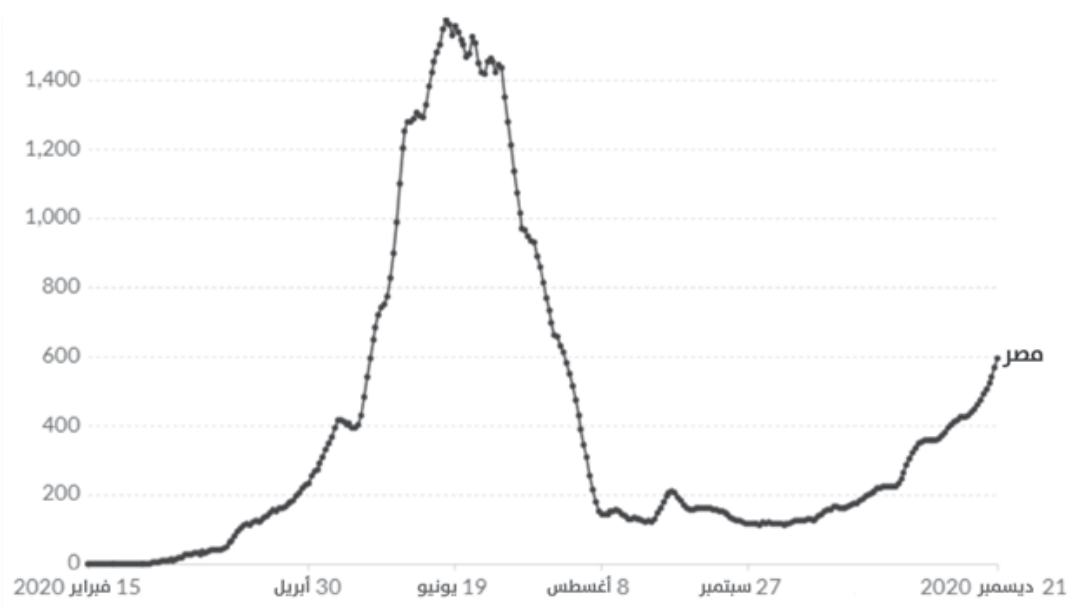

|

"COVID-19 Dashboard by the Center for Systems Science and Engineering (CSSE)," Johns Hopkins University (JHU), $22 / 12 / 2020$, accessed on 22/12/2020, at: https://bit.ly/3bRTIxi

يضاف إلى عامل الترهل في فرض إجراءات التباعد الاجتماعي ما رُصد من ضعف قدرة السلطات الصحية على كشف المرض، بسبب "انخفاض عدد اختبارات كورونا في مصر مؤخرًا"؛ فمعدلات الاختبار في مصر ثابتة عند حد 32 لكل مئة ألف شخص، وهو ما يجعل فذجة تطور الوضع الوبائي في مصر وتوقع تطور معدلات انتشار المرض مهمة صعبة جدًا،

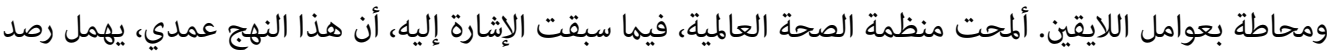


انتشار الوباء بين مجموعات واسعة من السكان. كما تبين تقارير مختلفة تناقض وجود نسبة مرتفعة من الحالات المكتشفة يتم حجزها في المستشفيات مع الأرقام المعلنة، ما يشير إلى وجود حالات أخرى لا يتم الإبلاغ عنها (12).

\section{2. الاستجابة الاقتصادية: موازنة المخاطر الصحية بالضرورات الاقتصادية}

أسفرت الإجراءات المتعلقة بالطارئ الصحي عن فرض التباعد الاجتماعي في القطاعات الإنتاجية والخدمية، وتوقف العديد من النشاطات، فقد صدر قرار يفرض حظرًا جزئيًا للتجوال، ترافق مع وقف رحلات الطيران الخارجية من مصر وإليها، ووقف الدراسة النظامية في المدارس والجامعات، إضافة إلى غلق المقاهي والنوادي الليلية، وغلق صالات الطعام في المطاعم ومجمعات التسوق(13). وفي مواجهة الانكماش المتوقع إثر الإغلاق، صاغت الحكومية حزمة من إلى إلى

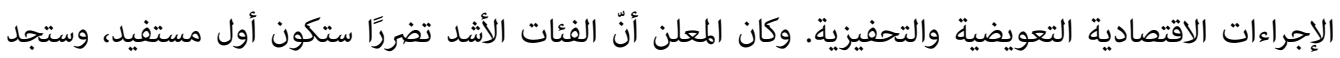
العون والتعويض. لكن ما جرى مل يحقق ذلك. ويبين هذا الجزء من التقرير ما نزعم أنه انحياز متجذر في السياسات الاقتصادية، انعكس على تلك الإجراءات على نحو يجعلها تصب في صالح فئات بعينها، في حين تهمل الفئة الأشد تضررًا من فقراء المصريين.

توقّع صندوق النقد الدولي، على غرار ما جرى توقّعه بالنسبة إلى بلدان العالم المختلفة، أن يمر الاقتصاد المصري بفترة

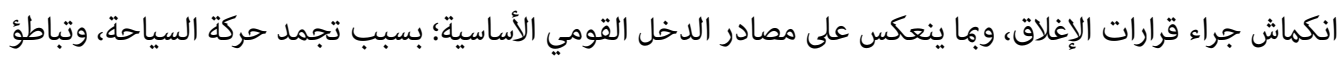

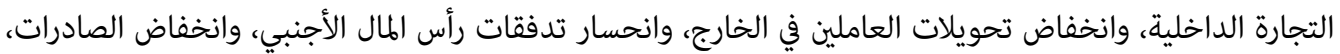
هذا إضافة إلى انحسار عائدات قناة السويس إلى أدنى مستوياتها(14). وفي خضم موجة الإغلاق العالمي، سارعت الحكومة إلى فرض مجموعة من التدابير الاقتصادية لمواجهة الوضع، وطرحت برنامجًا للإنقاذ بلغت نسبته 1.8 في المئة من الناتج المحلي، أي 100 مليار جنيه (نحو 6.4 مليارات دولار أميركي، تحت مسمى حزمة التحفيز الاقتصادي).

$$
\text { ويكن تصنيف ما حوته الاستجابة الاقتصادية وفقًا لثلاث مجموعات من القرارات، هي: }
$$

قرارات استهدفت تعزيز السياسة الاقتصادية، عبر تحفيز جانب العرض والإنتاج، وشملت تخفيضات

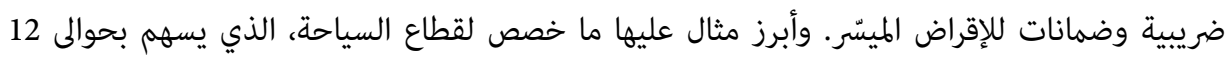

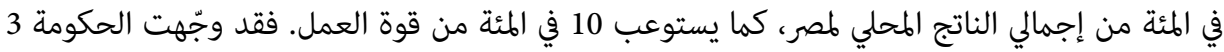
مليارات جنيه في شكل قروض ميسرة منخفضة الفائدة يضمنها البنك المركزي لفائدة الشركات العاملة في

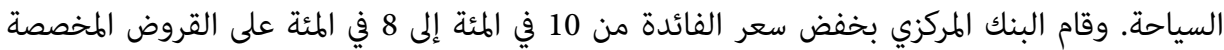
للقطاع مثله مثل قطاعات الصناعة والزراعة والتشييد. واستفاد القطاع من قرارات تخفيض أسعار الطاقة

$$
\text { والإعفاء من الضرائب العقارية. }
$$

12 "لا توصي بإغلاق المدارس.. 'الصحة العالمية' تحذر مصر من موجة ثانية لـكورونا"'، مصراوي، 2020/10/29، شوهد في 2020/12/3، في: 
ب. قرارات استهدفت تعزيز السياسة المالية والنقدية، عبر التوسع في سياسات القروض لمجابهة تقلب أسعار الصرف واضطراب الأسواق المالية. وكان من المثير أن يتم تضمين الحزمة برنامجًا لشراء الأسهم بقيمة 20

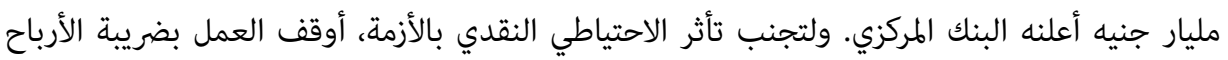

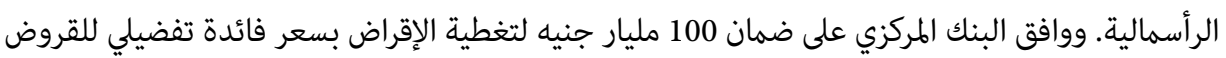
الموجهة إلى قطاعات الصناعة والزراعة والمقاولات، وقروض بفترة سماح مدة عامين للشركات العاملة في قطاع الطيران. ج. قرارات استهدفت تحفيز جانب الاستهلاك ودعم الفئات المتضررة، حيث خصص ما قيمته 10 مليارات جنيه مصري في شكل تيسيرات للقروض منخفضة الفائدة والتي تسدد خلال عامين، لشراء السلع الاستهلاكية.

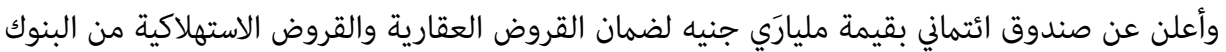

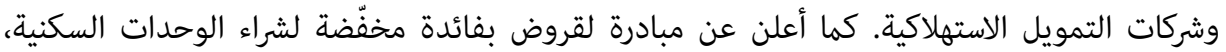

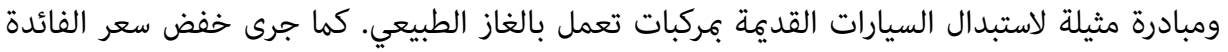

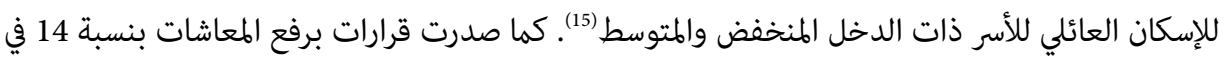

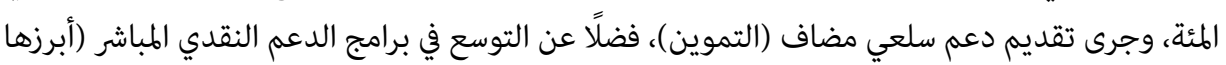

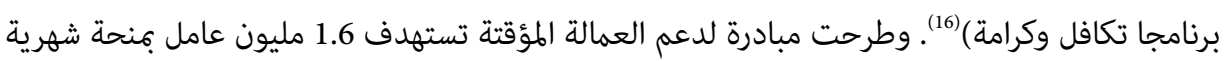

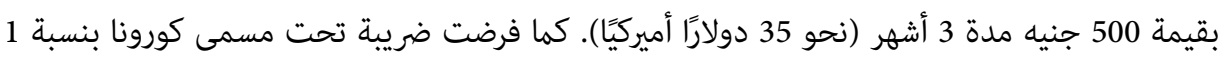

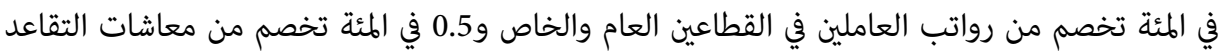

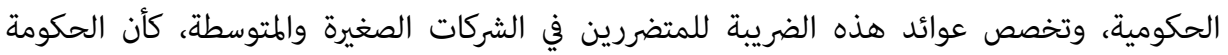

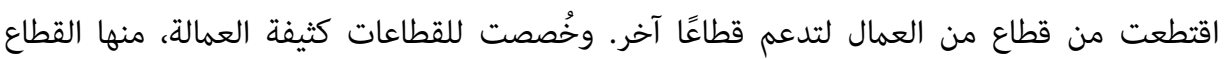

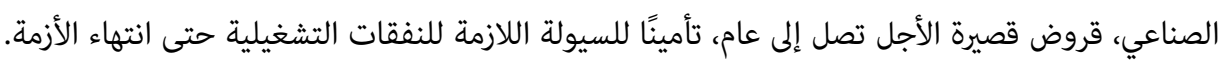

\section{3. الاستجابة السياسية: استمرار المقاربة الأمنية لعلاقات المجتمع والدولة}

من الوجهة السياسية، يمكن وصف الإجراءات التي اتخذتها الحكومة المصرية لاحتواء كورونا بأنها "مفاقمة لوضع سلطوي قائم؛ فقد استثمرت ظروف الطارئ الصحي لتشديد حالة الطوارئ السياسية التي تعيشها البلاد منذ

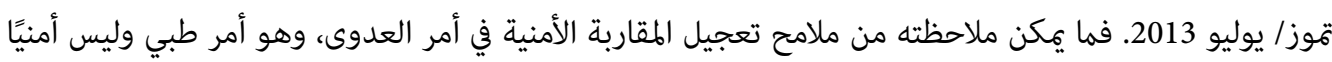

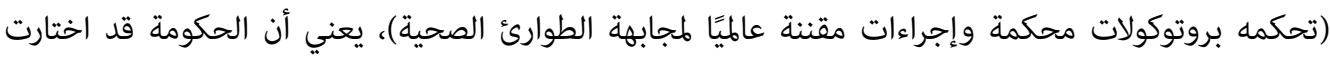

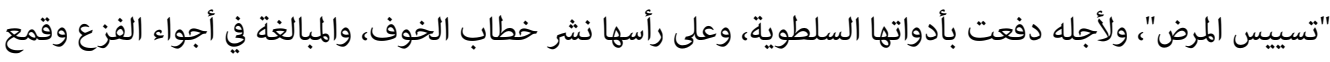

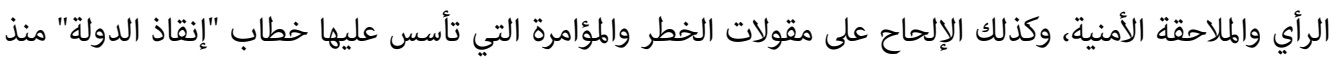
الانقلاب(17). م يقتصر الحال على إحكام القبضة الأمنية عبر تعديلات على قانون الطوارئ رقم 162 لسنة 1958 مبا

15 يجب ملاحظة أن مسألة خفض أسعار الفائدة كانت مقررة قبل الجائحة ومرتبطة بتغير الفائدة على الدولار عالميًا.

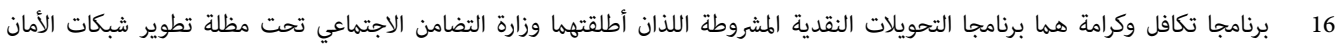

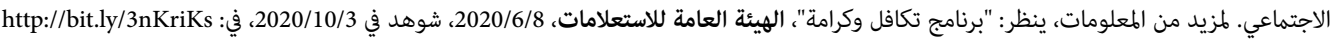

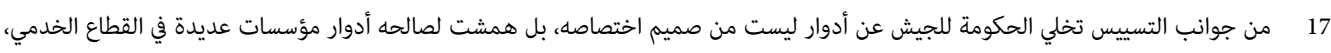

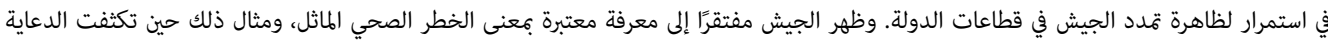

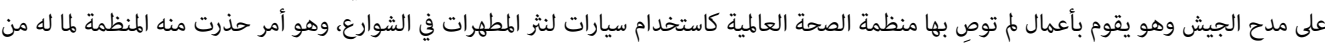
آثار وخيمة على الصحة العامة، ووجهت النقد الشديد إلى السلطات التي تقوم به. 
أضاف إلى سلطة رئيس الجمهورية والقضاء العسكري المزيد من القدرات القمعية، بل جرى تعزيز أدوات الإعلام التعبوي الموجه، وتضاعف خطابها المشيطن للمعارضة، كما أطلقت يد قوى الأمن في قمع المجموعات الاجتماعية

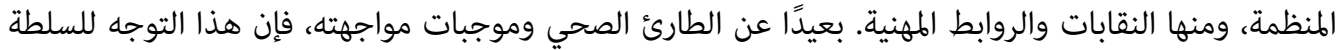

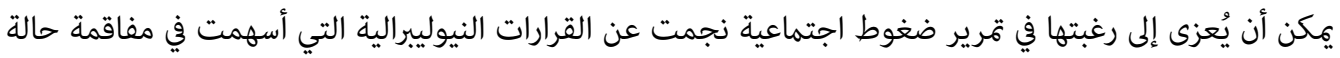
الفقر، وضغوط سياسية سبّبتها موجة احتجاجية كانت قد سبقت الجائحة ببضعة أسابيع. توازت مع الخطاب الحكومي موجة متناسقة في الإعلام الرسمي وشبه الرسمي، حاولت التهوين من المخاطر التي

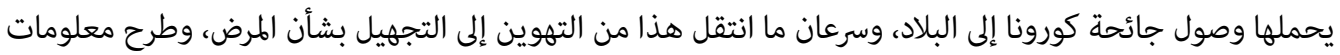

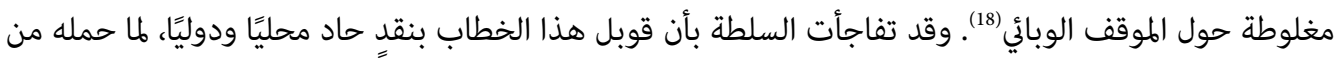

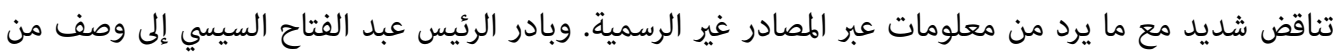

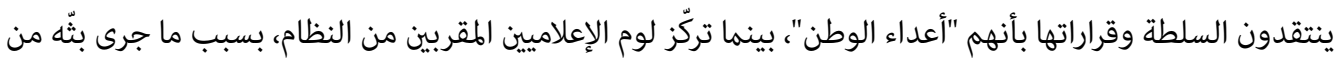

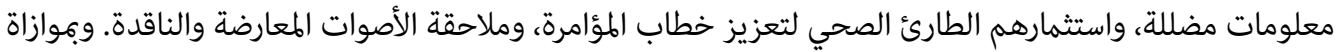
هذا الخطاب، لوحظ توجيه خطاب ديني مساير لموجة التهوين والتجهيل، تصدّره وزير الأوقاف الذي حفلت خطبه

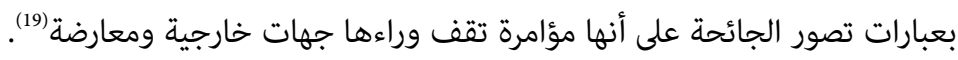

في هذه الأجواء، جرى التوسع في حجب المواقع الصحفية المستقلة وعرقلة عمل الصحافيين، فضلًا عن اعتقال بعضهم على خلفية الجدل حول صحة البيانات التي تظهرها الحكومة، أو نقلهم شكاوى مواطنين حُرموا من الرعاية الصحية الواجبة. وقد جرى منع المواطنين، ومنهم العاملون في مجال الرعاية الصحية من التعبير عن انتقاداتهم للسياسات

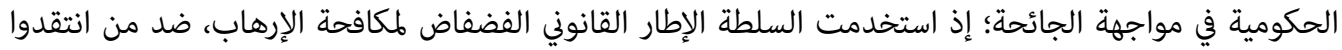

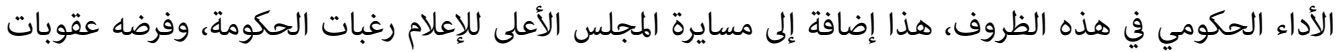

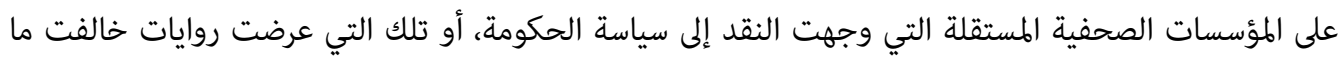

على مستوى الاستحقاقات الانتخابية، مل يعلن أي قرار بتأجيل الجولات الانتخابية المقررة في عام 2020، والتي تشمل

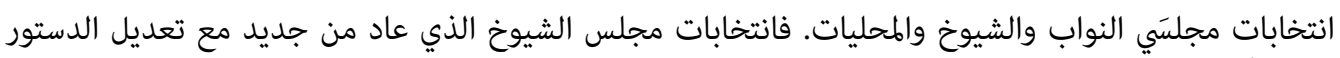

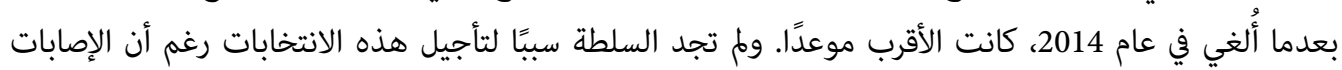

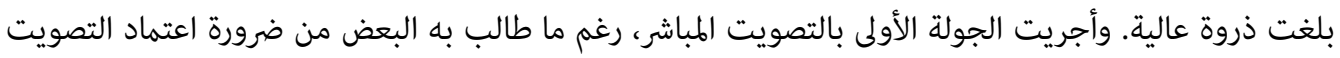

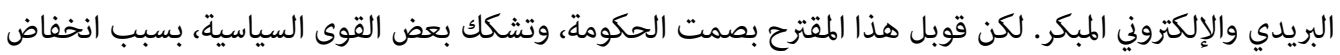

18

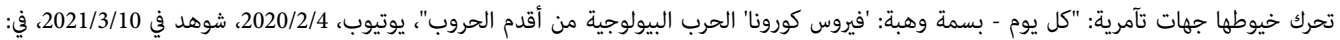

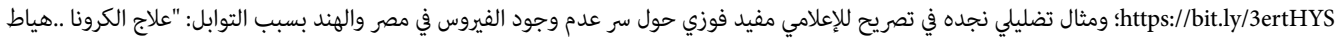

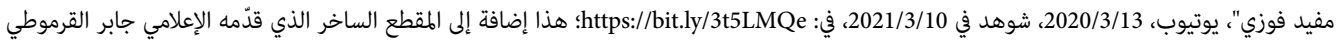

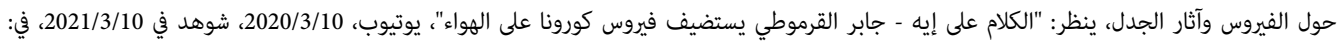

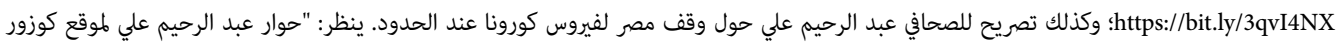

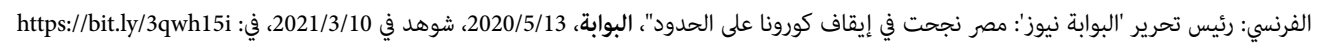

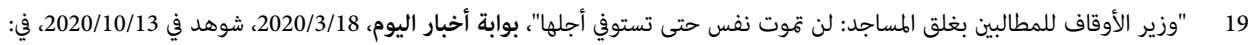
https://bit.ly/38xzPtV 
مستوى الثقة بأن تتولى السلطة مثل هذه التحديثات. وبالفعل، أعلنت الهيئة العليا للانتخابات جدولًا لانتخابات

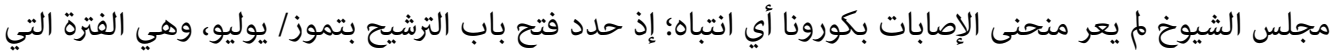

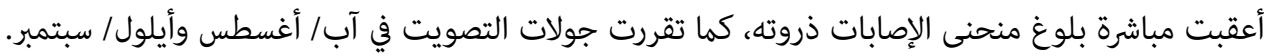

جرت العملية الانتخابية، وكان الإقبال على المشاركة فيها محدودًا جدًا، بحيث اعتبرت هذه المشاركة الأقل في

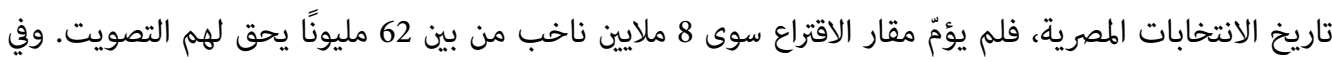

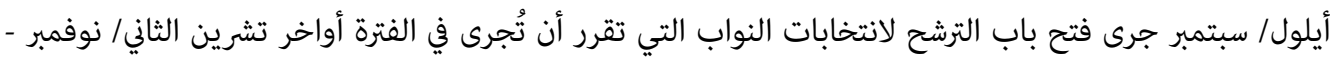

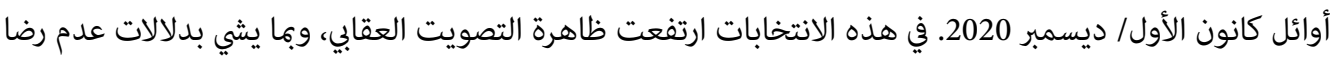

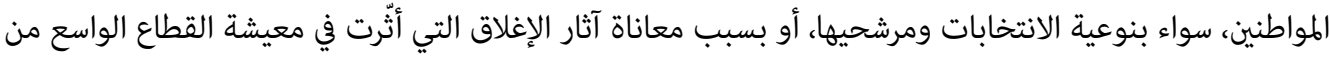
المصريين وم تسعفها استجابات الدولة.

على المستوى الدولي، مارست مصر دبلوماسية صحية في خلال فترة الذروة، بإعطاء منح من التجهيزات وأدوات الوقاية الخاصة بهواجهة الجائحة، لبعض الدول التي عانت وصول الجائحة إلى مستويات مهلكة، منها إيطاليا

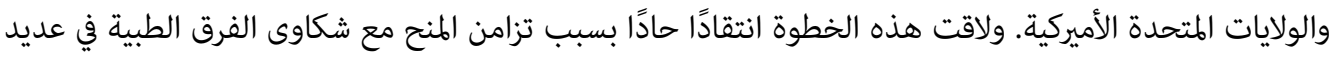
المستشفيات المتعاملة مع حالات الإصابة من نقص الإمدادات الطبية وأدوات الوقاية.

\section{ثانيًا: تقييم الاستجابات السياساتية في مواجهة الجائحة}

يكن إيراد تقييم للاستجابات وفقًا لتحقيق الغاية من الاستجابة، وبيان تكافؤ السياسة مع الأولويات التنموية والاجتماعية. نعرض فيما يلي تقييم الاستجابات الصحية والاقتصادية والسياسية.

1. تقييم الاستجابة الصحية: الديموغرافيا توازن ضعف استجابة النظاهم الصحيي يككن القول إن الديموغرافيا كانت عنصر الموازنة أو جبر ما عجزت قدرات النظام الصحي عن استيعابه. وأن السيناريوهات الأسوأ لم تقع بسبب الانتقال الديموغرافي وميزة أن الكتلة العمرية الأكبر من السكان هي هي من النمات الشباب. كشف الجدل الذي دار حول الانخفاض في نسبة المصابين بالفيروس نسبةً إلى عدد السكان الإجمالي هذه المفارقة. وظل المعلن من إحصاءات الإصابة محدودًا، ونسبة الوفيات من بين الإصابات المعلنة كبيرة نسبيًا مقارنة بدول

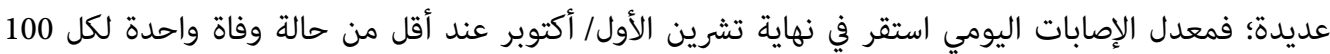

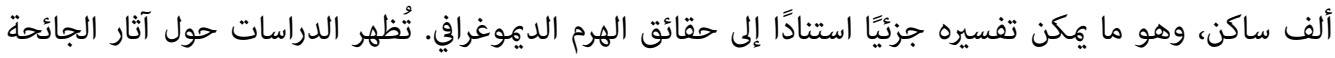

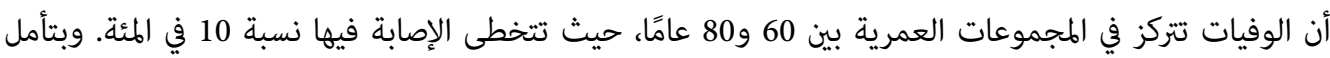

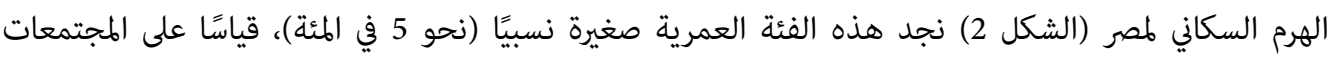

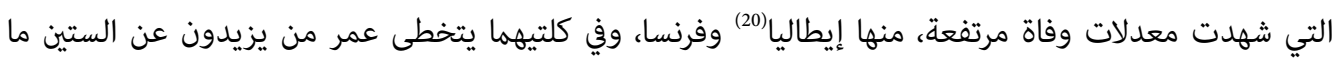

$$
\text { يقارب ربع السكان. }
$$

20 Tomáš Sobotka et al., "Age, Gender and COVID-19 Infections," MedRxiv, 26/5/2020, accessed on 10/3/2021, at: https://bit.ly/3rv5KTY 


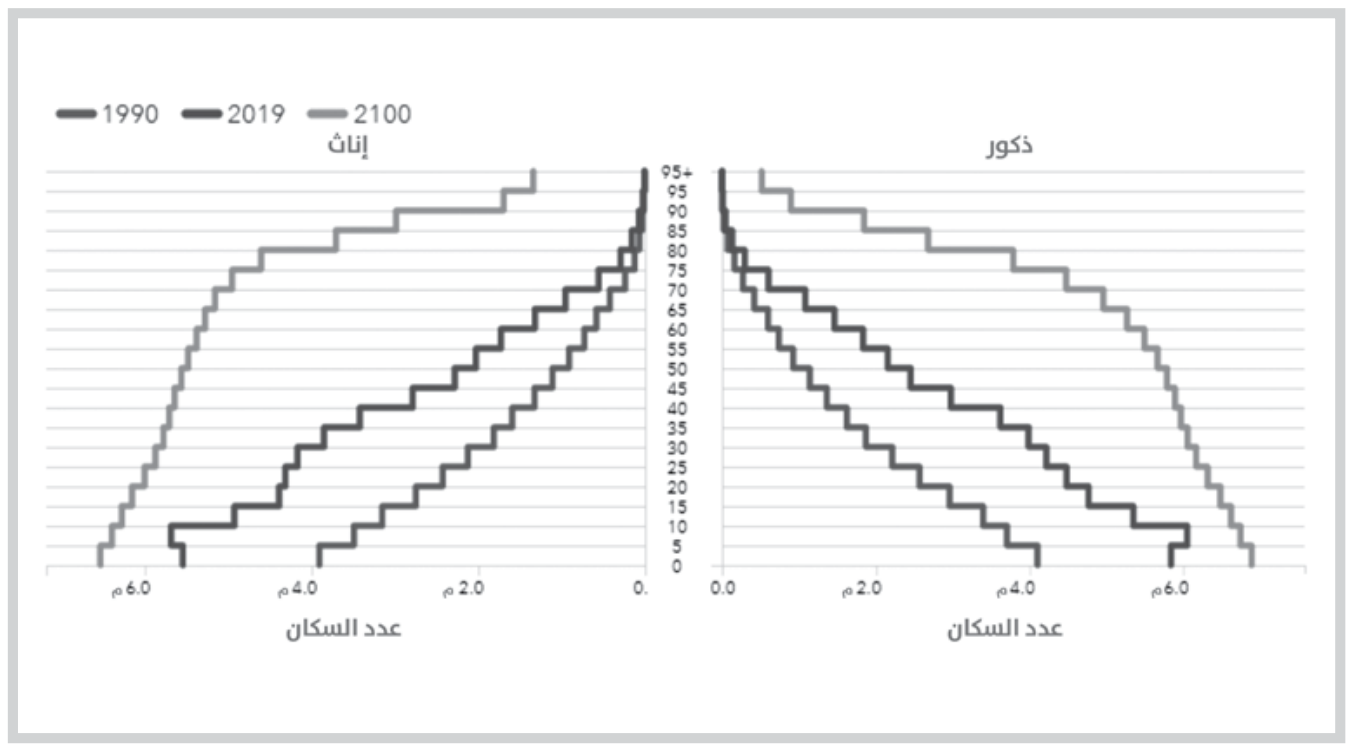

المصدر: استنادًا إلى:

Stein Emil Vollset et al. "Fertility, Mortality, Migration, and Population Scenarios for 195 Countries and Territories from 2017 to 2100: A Forecasting Analysis for the Global Burden of Disease Study," The Lancet, vol. 396, no. 10258

(October 2020), accessed on 18/3/2021, at: https://bit.ly/3vlIJ8u

جدير بالذكر أن عدة مصادر أكاديمية تحدت البيانات التي أعلنت عنها وزارة الصحة بخصوص المرصود والمتوقع من

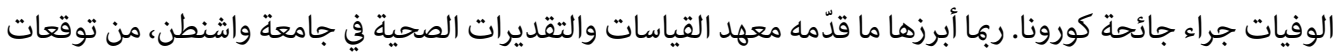

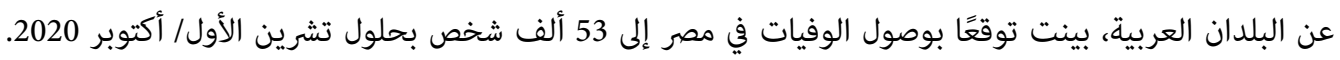
وقد استندت هذه التوقعات إلى نوذج يبني على قدرات النظام الصحي وطبيعة الإصابات، بمؤشرات من مثل

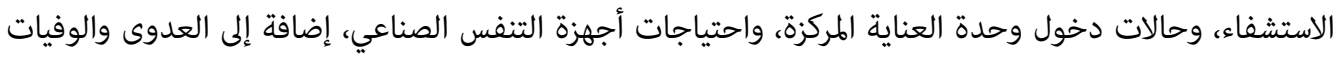
ونسبة الأجسام المضادة Antibodies. وتشمل العوامل الأخرى توقعات عدد الفحوصات، والتنقل (21). وهو السيناريو الأسوأ في مقابل توقعات بوفاة 21 ألف شخص في العراق و19 ألف شخص في المملكة العربية السعودية. لكن بعيدًا عن التشكيك في الأرقام الحكومية، وهو جدل لا يزال قائًا، تبقى المفارقة كامنة في معدل انتقال المرض من

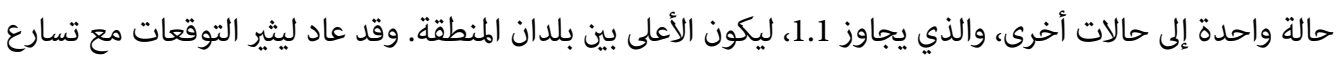

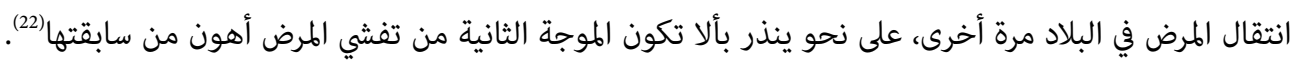

ضعف استجابات النظام الصحي لا يجد تفسيره في سوء إدارة المنظومة فحسب، بل يتصل بعوامل هيكلية تحذّ ردّا

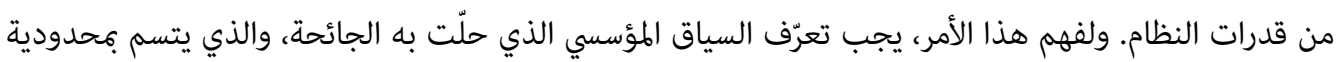

21 "New IHME COVID-19 Forecasts for Arab League Nations Find More than 50,000 Deaths in Egypt," IHME, 24/6/2020, accessed on $15 / 12 / 2020$, at: https://bit.ly/3kZP1G2 
الموارد؛ يُلمح تقرير لمنظمة التعاون الاقتصادي والتنمية(23) حول أثر جائحة كورونا في الاقتصادات النامية في المنطقة

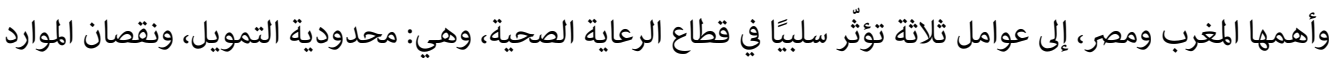

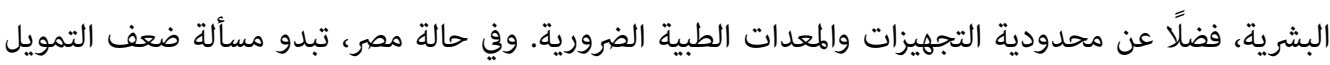
ضاغطة إلى حدً بعيد.

كما أظهرت بيانات صندوق النقد الدولي أنّ الإنفاق على الصحة في منطقة الشرق الأوسط لا يزال ضعيفًا في العموم،

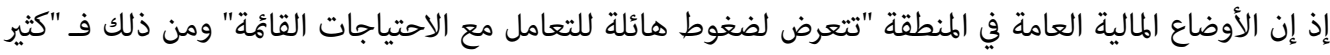

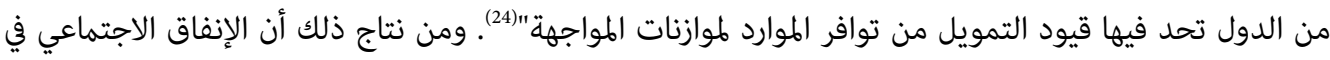
المنطقة يظل أقل مقارنة بمناطق العالم الأخرى. تنفق الحكومات العربية ما نسبته 10.4 في المئة من الناتج المحلي الماتي الإجمالي في المتوسط، وهي نسبة محدودة إذا ما قورنت بالنسبة المتحققة في الأسواق الناشئة وتقدّر بـ 14.2 في

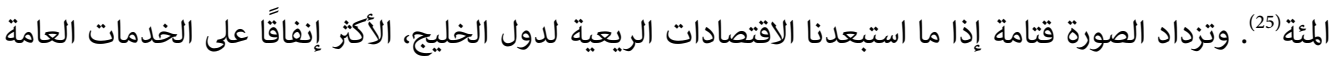

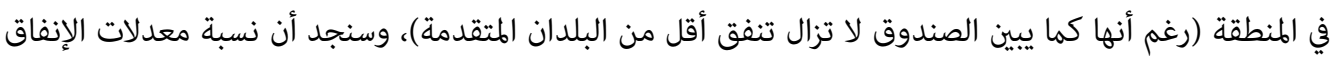

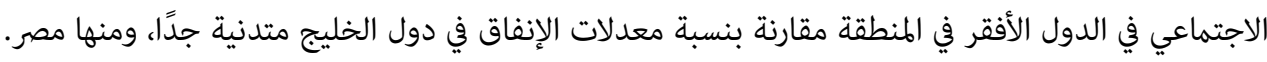
تتهرب الحكومة من تناول قضية ضعف الإنفاق الاجتماعي في مصر، وبالخصوص التزامها الواجب دستوريًا بنسب

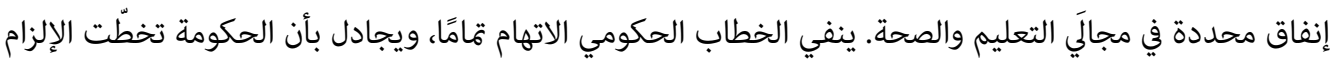

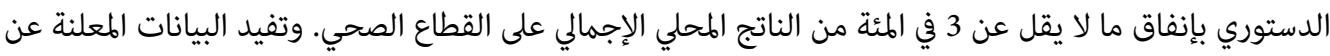

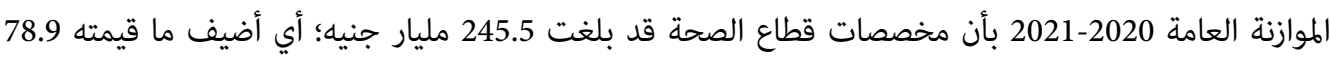
مليار جنيه، بنسبة زيادة تقدّر بـ 45 في المئة مقارنة بالعام المالي السابق.

أثير الأمر في البرلان، في مواجهة الوزيرة؛ إذ حثّها أحد أعضاء مجلس النواب على الاهتمام بمسألة تدنّي الإنفاق على ألى

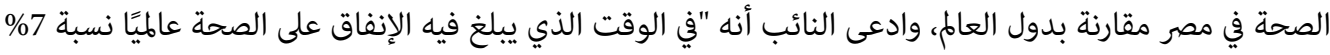
من الناتج المحلي الإجمالي و20\% من إجمالي الإنفاق الحكومي، نجد أنّ مصر لا يتجاوز فيها الإنفاق على الصحة

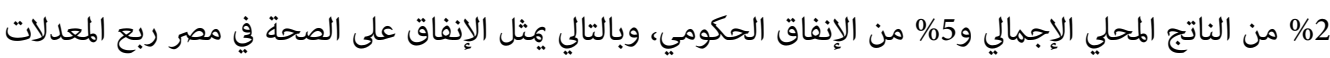

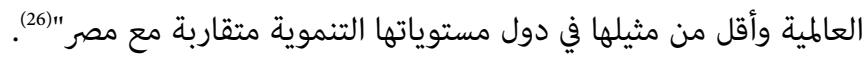
يمثل ما تعلنه الحكومة من أرقام مراوغة حسابية. ويشكك عدد من خبراء المالية العامة في صحة المعنى الذي تستخلصه

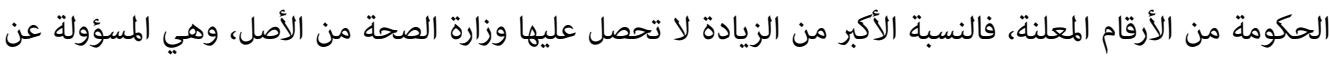
إدارة القطاع الصحي العام. وجرى إقحام مخصصات لهيئات ومؤسسات اقتصادية وشركات عامة أخرى على بند

23 "COVID-19 Crisis Response in MENA Countries," OECD Policy Responses to Coronavirus (COVID-19), 6/11/2020, accessed on 5/12/2020, at: http://bit.ly/2LNfNnk

24 وليد مجدي الهواري، "صندوق النقد يحث على زيادة الإنفاق الاجتماعي بالشرق الأوسط وآسيا الوسطى"، المصري اليوم، 2020/9/29، شوهد في https://bit.ly/3qLrolF 2021/2/29

25 ديفيد باربوشيا، "صندوق النقد يحث على زيادة الإنفاق الاجتماعي بالشرق الأوسط وآسيا الوسطى"، رويترز، 2020/9/29، شوهد في 2021/1/29، في: https://reut.rs/3en0WfP

26 من مداخلة النائب محمد فؤاد في جلسة مجلس النواب ـ ينظر: سمر نبيه، "نائب يطالب الحكومة بزيادة الإنفاق على الصحة: وضعها متدن"، الوطن،

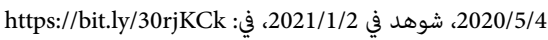


الشكل (3)

عدد الأطباء بالنسبة إلى كل 10 آلاف نسمة

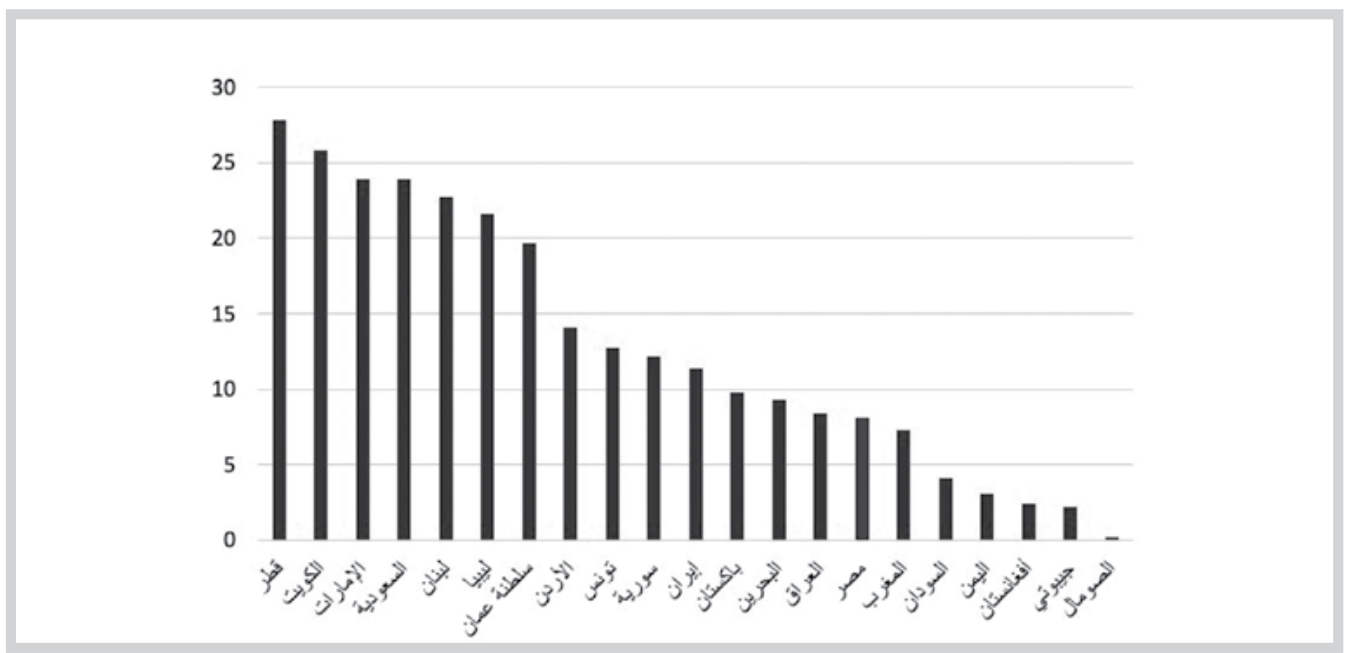

المصدر: نقلاً عن البيانات المنشورة في دراسة: "احتياجات سوق العمل المصري من المهن الطبية"، وزارة الصحة والمجلس الأعلى للجامعات، أيار / مايو 2019.

الإنفاق على الصحة، بل شمل الحساب نصيب وزارة الصحة من خدمات الديون، وهي نسبة مقتطعة، لا تدخل أصلًا في الإنفاق الحقيقي على الصحة. أما الأمر الأشد إثارة للنقد فتمثل في إضافة الحكومة مخصصات كبيرة لتطوير شبكات الصرف على أنها تقع ضمن الإنفاق الصحي. ويتضح التناقض إذا أجرينا الحساب وفقًا للتصنيف الوظيفي للموازنة؛ إذ يبين أن نسبة الإنفاق على الصحة دون الحد الدستوري، ومل تتجاوز 1.37 في المئة من الناتج المحلي الإجمالي (27). يتلازم نقص التمويل في قطاع الصحة مع نقص في المورد البشري من ناحية تأهله وتوزيعه. والجدل قائم منذ سنوات بشأن الحجم الحقيقي للعاملين في القطاع الصحي وبالخصوص الأطباء، في ظل صعوبة تكتنف الحصول على إحصاءات موثوقة حول أعداد العاملين. إن عدد المختصين في تقديم الخدمة الصحية لكل ألف من السكان يظل دون الحد الذي توصي به منظمة الصحة العالية والبالغ 4.45 أطباء وممرضين وقابلة لكل ألف من السكان. لا يزال عدد من يخدمهم الطبيب الواحد في مصر من التخصصات البشرية يتخطى 800 نسمة، بينما يتخطى العدد لطبيب الأسنان الواحد 4 آلاف نسمة، وكل 1840 نسمة يخدمهم صيدلي واحد. يرى البعض أن هذه النسبة مقارنة ببلدان ذات مستوى اقتصادي واجتماعي مماثل لمصر، هي نسبة جيدة. لكن خلافًا لذلك، ثُة من يرى أن "اختلالات خطيرة" أصابت توزيع العاملين في القطاع، فتجد في المحافظات الكبرى فائضًا من الأطباء في بعض المنشآت الصحية في المراكز الحضرية الكبرى، لكن تعاني المناطق الريفية والنائية داخل المحافظة نفسها انخفاضًا في عدد الأطباء. وثمة تخصصات منها الرعاية الأولية وطب الأسرة وممرضات المجتمع والممرضات المؤهلات، تشهد في العموم نقصًا حادًا، كما يرصد النقص بالنسبة إلى 
فنيي المعامل والأشعة والمراقبين الصحيين. أما في التخصصات الطبية النادرة، فالمؤسسات الصحية التابعة للوزارة تفتقر بشدة إلى المتخصصين في جراحة المخ والأعصاب وجراحة الأوعية الدموية وجراحات القلب المفتوح(28).

والسؤال المطروح هو: هل حالت هذه الصعوبات دون المواجهة الفاعلة؟ حقيقة الأمر أن الحكومة قد عمدت إلى موازنة هذه القدرات المحدودة عبر اتخاذ تدابير احتواء قوية في بداية الأزمة لتجبر ما تعرفه من ضعف هيكلي في النظام الصحي. وربما يرجع الفضل لهذا التحوط في انخفاض عدد الإصابات والوفيات في الفترة آذار/ مارس وذروة الإصابات في حزيران/ يونيو 2020. لكن المسارعة إلى رفع تلك الإجراءات وما تبعها من تصاعد في الإصابات، ترك أثره الواضح في النظام الصحي، إذ بات يعاني ضغط ما يفد إليه من الحالات، وطلبات العناية الطارئة. من جهة إتاحة الخدمة، بينت الموجة الأولى للجائحة مقدار ما تعانيه أغلب مناطق البلاد من نقص في الرعاية

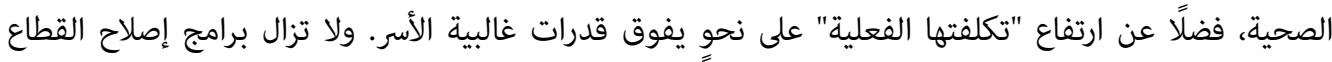
الصحي التي تعلنها الحكومة غير قادرة على توفير نواتج تنموية معتبرة في هذا القطاع تعيد ضبط اختلالات التوزيع، تهات سواء على مستوى إتاحة الخدمة أم التغطية التأمينية أم تحسين جودة الخدمات الصحية العامة منها والتخصصية. وبالرغم من اتساع قاعدة الخدمة الطبية في مصر، فإنّ نوعية الخدمة لا تزال تقيَّم بالمنخفضة، فضلًا عن سوء توزيع هذه الخدمات؛ إذ يقتصر توافر خدمة صحية ذات جودة معتبرة على عدد محدود من المراكز التخصصية والطستشفيات الجامعية والخاصة، في نطاق العاصمة، وبعض المدن الرئيسة في شمال البلاد، في حين يختل توزيع الخدمات الصحية بشدة على باقي المحافظات (29). ورغم مساعٍ تسارعت في العقد الأخير لتخفيف حدة وشكات مشكل التوزيع، عبر بناء مستشفيات جديدة في بعض المحافظات المحرومة، فإن المؤسسات الطبية الكبيرة تبقى متركزة في العاصمة، بما في ذلك المستشفيات التابعة للقوات المسلحة التي بدأت في تقديم خدماتها للمدنيين (30).

\section{2. تقييم الاستجابة الاقتصادية: من يتحمل تكلفة الجائحة؟}

في العموم، بينت المؤشرات الاقتصادية الأساسية تحسنًا نسبيًا في أداء الاقتصاد المصري في عام الجائحة، وأنه بدا في حالٍ أفضل مقارنة بالعديد من الاقتصادات المناظرة له في خصائصها ومستوى تطورها؛ إذ حقق فوًَا إيجابيًا قدّره

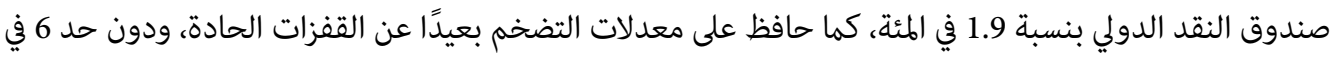

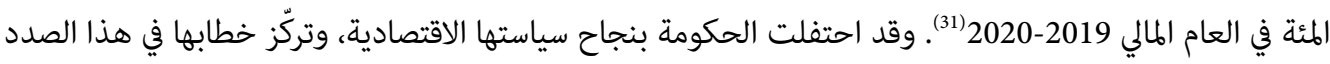
على مؤشرات غالبها مالي ليس تنمويًا، وأهمها النجاح في احتواء التضخم، والسيطرة على عجز الموازنة، مع الوصول

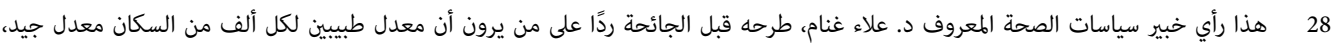

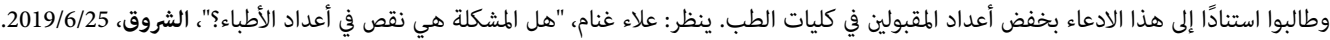

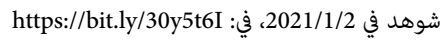

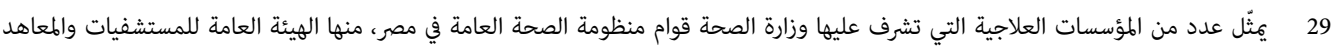

التعليمية، والهيئة العامة للتأمين الصحي، والأمانة العامة للمراكز الطبية المتخصصة، والمؤسسة العلاجية بالقاهرة، والهيئة العامة للعاهية العاية العاية الصحية.

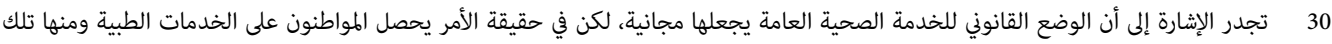

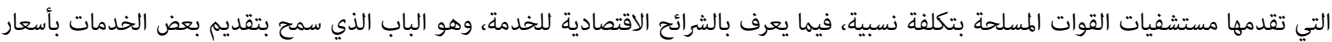

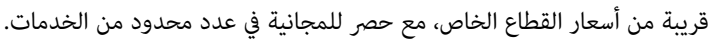

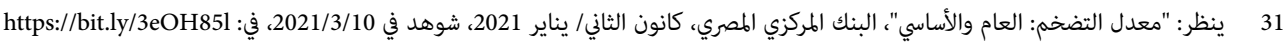


بالاحتياطات النقدية إلى مستوى 40 مليار دولار، ومما يغطي احتياجات البلاد مدة سبعة أشهر (32. وكذلك ما يتعلق بحماية العملة الوطنية، بعدما تعرّض الجنيه المعري للانخفاض في الربع الثاني من عام 2020 وفقد نحو 2 في المئة من قيمته، في ظل تراجع تدفقات الدولار وخروج رؤوس الأموال على نحوٍ متسارع (33). كما تراجعت، في إثر انخفاض الصادرات والانكماش في القطاع السياحي، وتراجع تحويلات العاملين في الخارج(34)، وانخفاض عوائد قناة السويس بانخفاض حركة التجارة العالهية. فقد استهدفت إجراءات التحفيز الاقتصادي إنقاذ هذا الوضع وإحداث فارق إيجابي على الجنيه، بالتوازي مع تخفيف إجراءات الإغلاق الاقتصادي واستعادة قطاع التصدير بعض قدراته، كما أعانت في هذا الأمر تدفقات القروض التي حصلت عليها مصر من صندوق النقد الدولي (35). أما عن معدلات البطالة في مصر، فقد تراجعت مع استعادة النشاطات الاقتصادية ورفع القيود(36. لكن عودة العمالة من بلدان الخليج، والتي أضافت نصف مليون إلى المعطلين، ضاعفت تفاقم أثر البطالة. كما أن استمرار إغلاق أبرز مجالات تشغيل العمالة، وهو قطاع السياحة الذي يستوعب وحده 10 في المئة من قوة العمل، فاقم الوضع، ومن المرجح أن يستمر في عام 2021 في ظل صعود منحنى الإصابات وبدء موجة أخرى من الإغلاق العالمي. فضلًا عن ذلك، تتضارب الأرقام حول البطالة الواسعة في القطاع غير الرسمي، والتي لا يتوقع أن تتراجع مع انخفاض معدلات التات التهات الإنتاج والتجارة الداخلية.

يقتضي الحديث عن الفئات المتأثرة بالإغلاق تناول أثر الفقر ومن يتحمل تكلفة الإغلاق فعليًا. وتبرهن المؤشرات

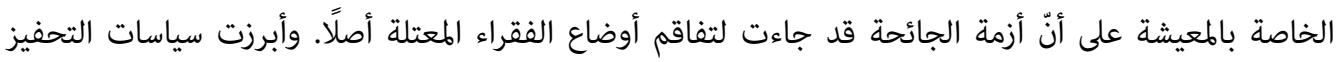

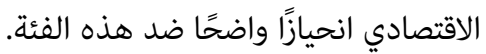

وتكشف ذلك مخصصات الموازنة التي تعمل من خلالها سياسات الدولة ومبادراتها للحد من آثار الجائحة. لقد

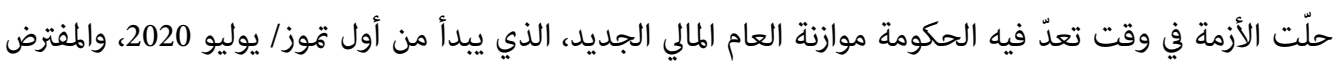
أنها كانت تستوعب ما تقتضيه المواجهة من تخصيص موارد استثنائية لجبر نقص التمويل الكبير في قطاع الصحة، ولاستيعاب الأثر الاقتصادي في معاش الفئات الأفقر، خصوصًا أن أغلبها لا يحظى بتغطية شبكات الضمان الاجتها لاجتماعي. لكن ما تمخضت عنه موازنة 2020-2021 جاء مناقضًا لهذه الضرورة الملحُة.

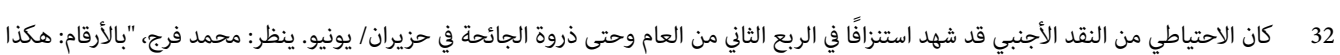

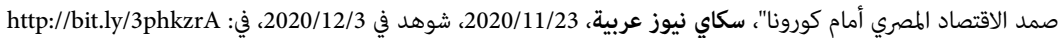

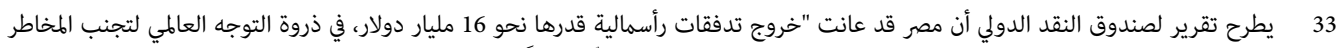

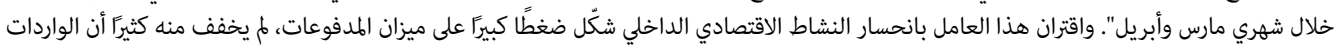

قد هبطت مع انخفاض الطلب المحلي. ينظر: "Egypt Takes Proactive Approach to Limit the Pandemic's Fallout," The International Monetary Fund, 9/7/2020, accessed on 10/12/2020, at: https://bit.ly/3en5C5n

34 كانت تحويلات العاملين في الخارج قد بلغت ذروتها قبل الجائحة في عام 2019 بتخطيها 26.8 مليار دولار، وبما يوازي 10 في المئة من الناتج المحلي.

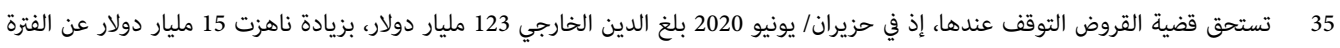

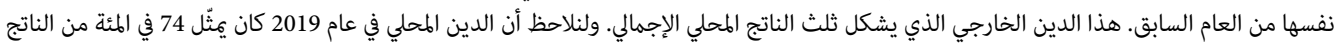
المحلي الإجمالي البالغ 332 مليار دولار أميركي.

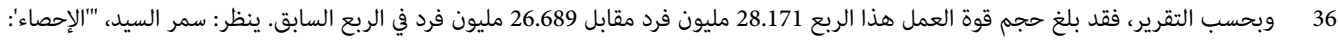

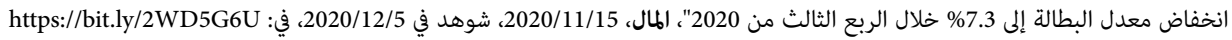


لقد أعلنت الحكومة أنها وضعت مخصصات استثنائية، بلغت 93 مليار جنيه، أضيفت إلى موازنة الصحة عن عام

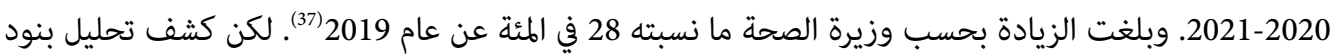

الميزانية أن التقشف يستمر عنوانًا للسياسات الصحية ومواردها.

ولنبدأ من الصورة العامة لوضع الدعم الموجّه إلى الفئات الأفقر. كان من المتوقع في الموازنة أن يتم تعزيز المزايا

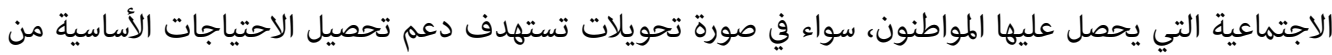

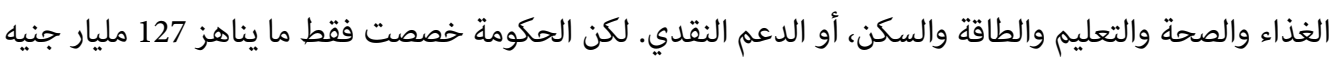
مصري (حوالى 8 مليارات دولار)(38)، أي ما يقل عن مخصصات الدعم المرصودة في العام السابق، مكتفية بتثبيت

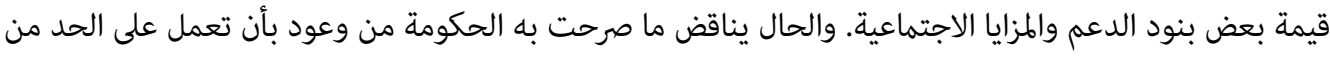

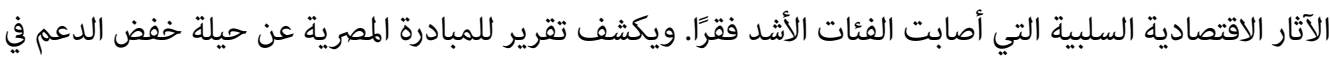
الموازنة، بنقل الوفورات المالية الناتجة من خفض الدعم العيني لأجل رفع بند الدعم النقدي (برنامجَا تكافل وكرامة).

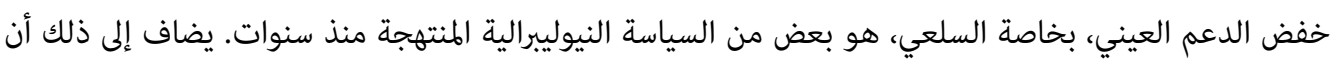

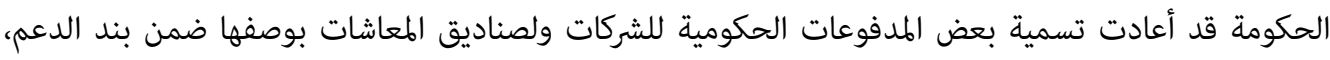
بينما هي مجرد سداد لديون مستحقة لهذه الجهات. واستمرت سياسة خفض الدعم التمويني، السياسة الهادفة

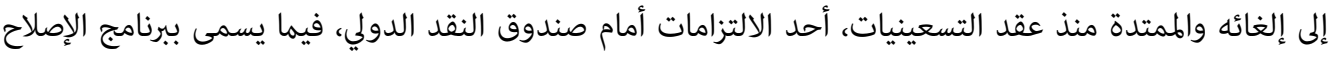

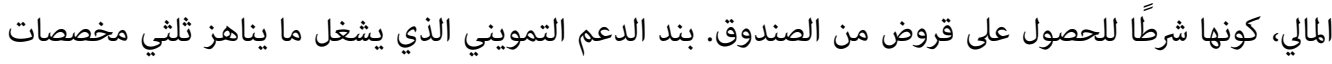

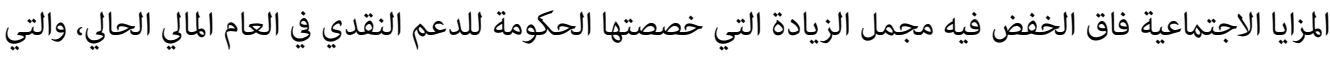

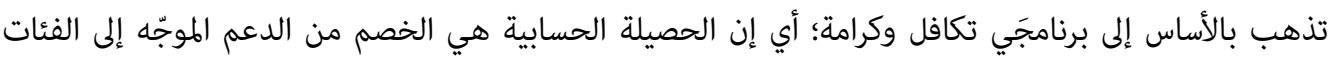

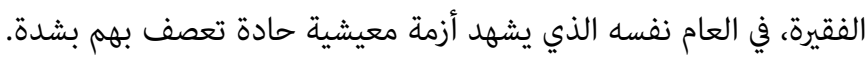

والملمح الأبرز لانحياز السياسات، هو ضآلة المبلغ المخصص للقطاع الصحي التابع للدولة من حزمة إنقاذٍ يُفترض فيها أنها جاءت لتعزز قدرات المواجهة، وتجبر العجز الشديد الذي تعانيه موازنة الصحة. مثّل هذا المبلغ ما نسبته 1 في المئة فقط من الحزمة (أي مليار جنيه). لا يعبّر هذا المبلغ عن تجاهل الحكومة ضعف ميزاهية الهنية الصحة فحسب،

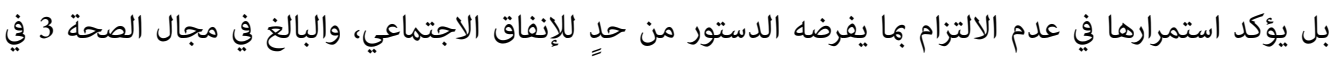

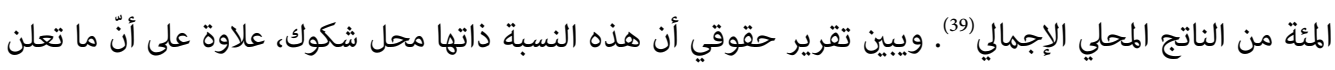
الحكومة أنه زيادة هو مجرد مراوغة حسابية، وتظل مخصصات الصحة من بين الأدنى في السنوات الماضية. ولا تزال الحاجة قائة إلى معالجة العجز في قدرات النظام الصحي، بخاصة في التجهيزات والأدوات المطلوبة بشدة لمواجهة الفيروس (كأجهزة التنفس الصناعي، وغرف العناية الفائقة، ومستلزمات الوقاية الطبية، وتأهيل مبانٍ لطوارئ العزل

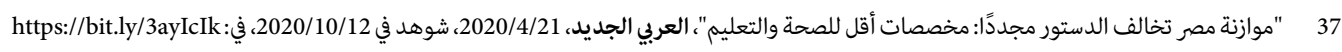

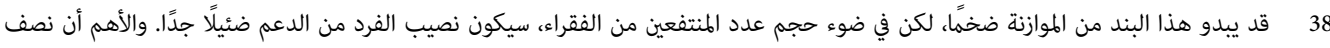

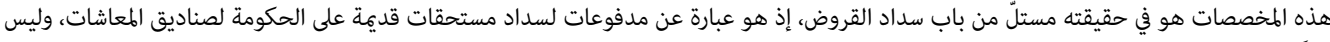

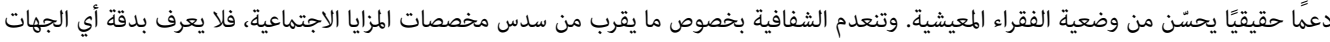

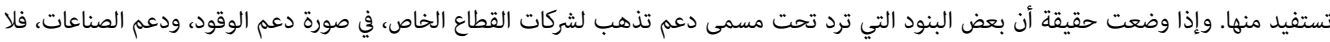

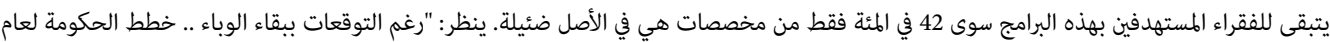

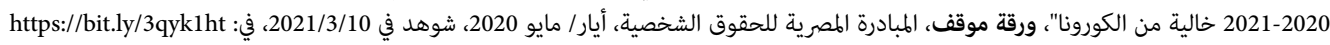


الطبي)(40). لكن "مجموع الإجراءات المعلَن عنها لا يزيد عن ربع مبلخ الزيادة المخطط لموازنة قطاع الصحة، ومن غير المعلوم فيمَ ينفق باقي المبلغ المخطط" (41). مُ يكن مستغربًا أمام هذا القصور أن يثور نقدُ حادّ في وجه الحكومة انطلاقًا من قلب القطاع الصحي ذاته، في ظل معاناته نقص التجهيزات وعدم عدالة التعويضات. وبالطبع ووجه النقد بتعامل أمني سنبينه في القسم التالي. 3. تقييم الاستجابة السياسية: استمرار المقاربة الأمنية لعلاقات المجتمع والدولة رغم الجائحة

تظهر الأزمة بين الحكومة ونقابة الأطباء بعدًا من مشكلة المقاربة الأمنية التي غلبت عليها الغايات السياسية، لا غايات إدارة الطارئ الصحي. فقد تفجر في الفترة أيار/ مايو - حزيران/ يونيو 2020 غضب الأطباء، بسبب ممارسات الوزارة وما وصف بتخبط قرارات الطوارئ الصحية، وفرض السلطة لأمور لا تتوافر تجهيزات طبية لتطبيقها، وتجاهلها حقيقة افتقار المستشفيات إلى أدوات الوقاية الضرورية لحماية الفرق الطبية. كان تصاعد حالات الإصابة والوفاة بين الفرق الطبية يُسعِر الغضب، ويحيي مطالب أقدم لهذه الفئة ممن تصاعدت شكواهم من سوء المعاملة وضعف الأجور وتعسف الإدارة. وقد ووجه هذا الموقف برد فعل أمني مُغالى فيه، وجرى رصد عديد الحالات التي واجه فيها أطباء علت أصواتهم بالنقد التعسف والتنكيل الإداري بل الاعتقال.

وقد وصلت الأزمة إلى ذروتها بسبب انفلات تصريحات المسؤولين ومنهم رئيس الوزراء نفسه، بتحميل الأطباء المسؤولية عن سوء الأداء في القطاع الصحي، وكانت سببًا في تصاعد الدعوات الاحتجاجية (22.) وقد ضخم من أثر التصريحات السلبية للمسؤولين ما رافقها من خطاب تحريضي ضد الأطباء جرى بثّه في الإعلام الرسمي وشبه الرسمي، وكذا ما اتخذ من إجراءات قمعية لحقت عددًا من الأطباء والعاملين في القطاع الصحي(43).

40 صرح السيسي في حزيران/ يونيو بأن القوات المسلحة أنشأت 6 مستشفيات جديدة جاهزة للتشغيل في حال تفاقمت أزمة الكورونا وفاقت قدرات وزارة

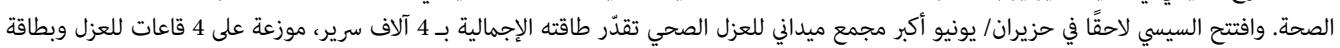

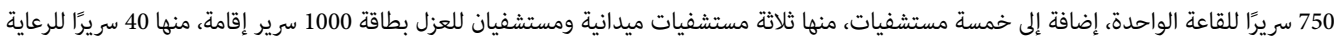

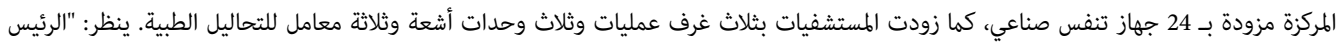

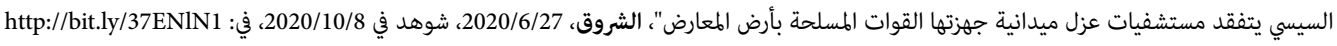

41

42 "فيروس كورونا: غضب أطباء بمصر لاتهام الحكومة لهم بالتسبب في ارتفاع الوفيات"، بي بي سي عربي، 2020/6/24، شوهد في https://bbc.in/38vsUSJ

43 يبين تقرير مستقل ازدياد "المهارسات الحكومية الرامية إلى التضييق على حق المواطنين في التعبير عن آرائهم، وتحديدًا فيما يخص تطورات الوضع الورات

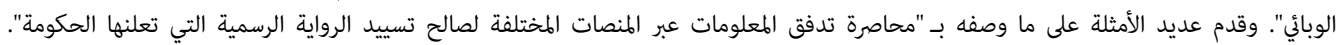

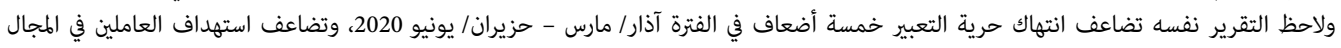

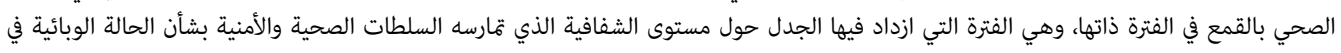

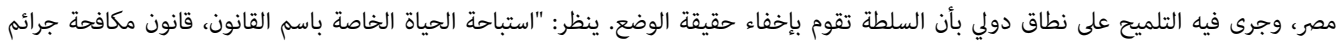

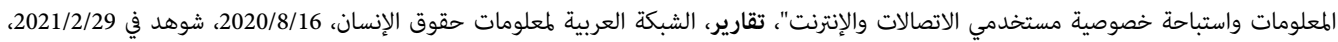

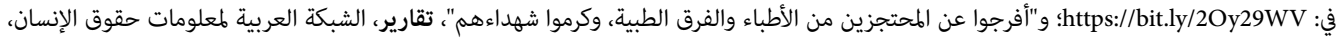

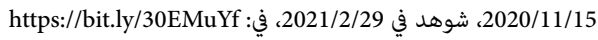


تصدرت النقابة مقاومة ما اعتبرته حملة منظمة، وأطلقت سلسلة من البيانات التي تنفي مسؤولية الأطباء عمّا وقع من تخبط، بل تتهم السلطة صراحة بالتحريض على الأطباء. في ظل هذه المواجهة، علت الخشية من الدعوة إلى

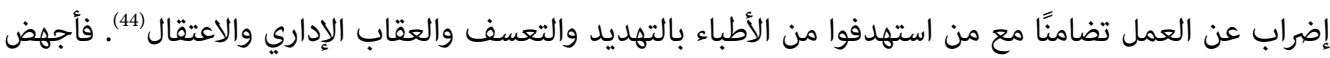
ثبات موقف النقابة هذا التوجه السلطوي، ودفع الحكومة إلى طلب تهدئة الأزمة، مع وعد منها بتوفير الموارد الوقائية والتجهيزات الضرورية، والحد من الخطاب الذي يحرض على الأطباء.

ربما لا تنفصل توجهات الأمن السياسي التي أطّرت التعامل في الأزمة مع نقابة الأطباء ومع الفرق الطبية عما جرى من مواجهة مع الصحافة العالهية، جراء الحساسية الشديدة من أي نقد خارجي للنظام وتناول شؤونه على نطاق الإعلام الدولي. فإثر نشر صحيفة الغارديان البريطانية خلاصة لدراسة إحصائية لباحث كندي (45)، زعمت أن الأعداد

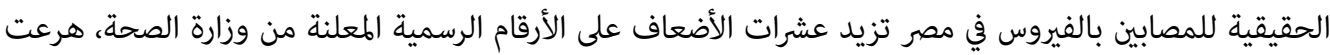

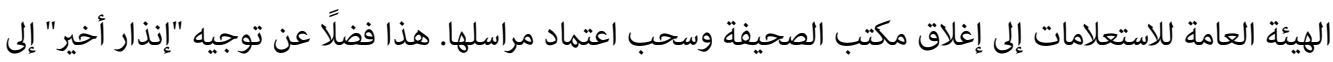

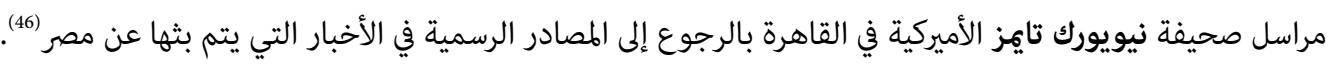
لاحقًا، وبسبب الانتقادات الداخلية والخارجية، جرت إعادة نظر واضحة لذلك الخطاب التعبوي وتم الحدّ من الإجراءات القمعية، وسمح بنقد نسبي للمؤسسات الصحية، وانسحبت نسبيًا المعالجة الأمنية لصالح عمل فني وتقني تشرف عليه لجان متخصصة. ربما أسهم في هذا التحسين ما فرضته المعايير العالية في التعامل مع الجائحة، وما ظهر من دروس مستفادة على المستوى الحكومي. لكن بالرغم من ذلك، مل يتوقف خطاب المسؤولين عن لوم المواطنين على ترهل إجراءات الإغلاق وضعف الالتزام بها.

\section{ثالثًا: مسارات التعافي من الأزمة}

نتناول في هذا القسم سيناريوهات التعافي ومساراته الططروحة على الطستويات الثلاثة، الصحية والاقتصادية والسياسية.

\section{1. التعافي الصحي: الجدل حول اللقاحات وقدرة مصر على إنتاجها}

منذ تشرين الثاني/ نوفمبر 2020، دار الجدل في استراتيجية الحكومة للوقاية من الجائحة، وبالخصوص في قدرتها على توفير اللقاحات للمواطنين. وشددت الوزارة من جانبها على قدرتها على توفير ما تحتاج إليه البلاد من الجرعات في فترة وجيزة، مع توكيد أن الأولوية في إعطاء اللقاح ستكون للأشخاص الأشد عرضة للإصابة بالفيروس، وعلى رأسيه أسهم

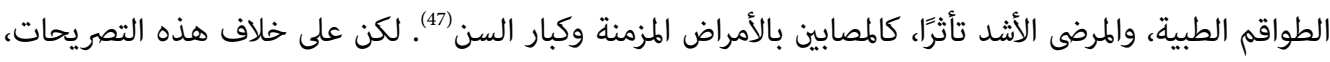

44 "Egypt Arrests Doctors, Silences Critics Over Virus Outbreak," The Washington Post, 9/7/2020, accessed on 10/10/2020, at: http://wapo.st/3mHvLMC

45 نشرت هذه الدراسة في مجلة The lancet infectious diseases، وقام عدد من أساتذة كليات الطب في مصر بنشر بحوث أخرى لاحقًا في المجلة نفسها تنتقد منهجية الدراسة ونتائجها.

46 ينظر نص قرار إنهاء الاعتماد لكراسلة الغارديان، وإنذار لراسل نيويورك تائز: الهيئة العامة للاستعلامات، 2020/3/17، شوهد في 2021/2/29، في: https://bit.ly/3rj8Tqk

47 مريم الخطري، "الصحة تكشف 4 فئات لها الأولوية في 'لقاح كورونا"'، الوطن، 2020/12/10، شوهد في 2020/12/20، في: https:/bit.ly/3tgzNzh 
وبالرغم من الإعلان عن حملة تطعيم عامة في مطلع آذار/ مارس 2021، مل تتضح حتى نهاية شباط/ فبراير ملامح استراتيجية متكاملة لتوزيع اللقاحات على الفئات السكانية، تتلاءم مع أولويات التطعيم التي توصي بها منظمة الصحة العالمية، بخاصة تشديدها على عدم التمييز في منح اللقاح. ما أعلنته الحكومة بخصوص ضمان الحصول على لقاح كورونا يشي بإيثارها، ككثير من دول المنطقة، عدم الاعتماد على مصدرٍ واحد للقاح، والسعي للحصول على أنواع من اللقاحات. وفي سبيل ذلك، تبين الخطوات المتخذة من الحكومة أنها تسير في مسارات ثلاثة، هي:

المشاركة في البحوث المتعلقة باللقاحات وفي إنتاجها. وثمة سعي للاستفادة مّا قلكه مصر من بنية تصنيع الدواء، وجعلها وكيلًا إقليميًا في المنطقة العربية وأفريقيا لبعض اللقاحات، وخاصة اللقاحين الصيني (سينوفارم) والروسي (سبوتنيك). وقد صرح عديد المسؤولين بتطلعهم إلى أن يكون لمصر حصة من الكاسب، بتحوّلها مركزًا إقليميًا لإعادة إنتاج وتوزيع ملايين الجرعات من اللقاحات التي تملك رخصها الشركات صاحبة حقوق الملكية

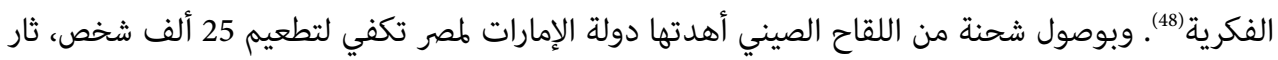
الجدل حول بدء الحكومة برنامجها لتطعيم المواطنين ضد كورونا بهذا اللقاح. ولم تَحْظ حجة مشاركة مصر

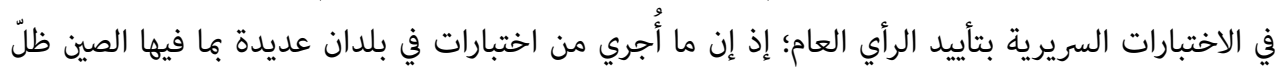
محاطًا بأمارات عدم الشفافية، وبما يطرح الشكوك حول أمان اللقاح. وتقول الحكومة المصرية إنها بنت ثقتها باللقاح الصيني استنادًا إلى إشراف منظمة الصحة العالمية على خطوات اختباره. وثمة ما يشير إلى توطين إنتاجه في مصر، بدعم إماراتي، بعدما حصلت هيئة المصل واللقاح المصرية على تكنولوجيا تصنيعه من الشركة الصينية. ولا يستبعد الخبراء أن يكون التفضيل المصري للقاح الصيني "مرتبطًا بتوافق سياسي بين البلدين". أما اللقاح تلناح الروسي، فلا يبدو أن التوافق بين مصر وروسيا حول التشارك في إنتاجه قد تم (49.).

ب. أما المسار الثاني فهو الحصول على القدر الأكبر من اللقاحات المنتجة في البلدان الغربية، والتي يتم توفيرها

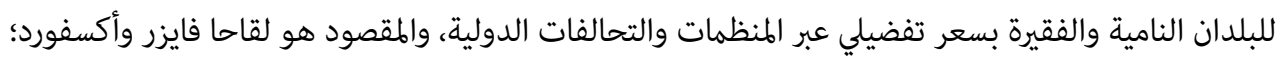
وقد أدرجت مصر على قوائم البلدان المستفيدة من برنامج الإتاحة العالمية للقاح كوفيد-19 "كوفاكس" COVAX، الذي دشنه تحالف اللقاح العالي "جافي" Gavi عبر منظمة الصحة العالهية. وهو تحالف يسعى مئى إلى تأمين أكثر من مليارين من جرعات اللقاح لتسعين دولة من دول العالم الفقيرة والنامية (50). وفي هذا السياق

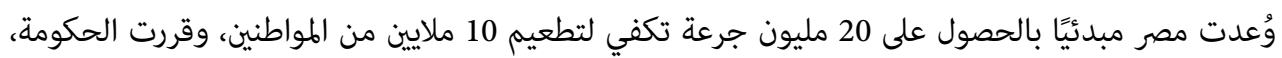
لتسريع هذه الخطوة، تفويض وزيرَي الصحة والمالية لإتمام الاتفاق.

48 Jared Malsin, "Covid-19 Vaccine Makers See Egypt as Crucial Launchpad," The Wall Street Journal, 26/10/2020, accessed on 20/12/2020, at: https://on.wsj.com/3cfuSI0

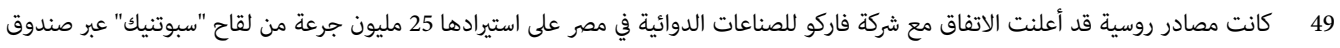

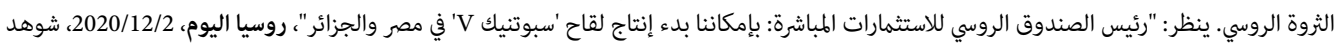
في 50 يضع برنامج كوفاكس مصر ضمن الفئة الثانية من البلدان ذات الدخل المتوسط المنخفض، من ثم ستحصل على اللقاح بأسعار مخفضة، ما مُ تُوصِ دول مانحة بإعطاء مصر جرعات بالمجان على حسابها. 
ج. أخيرًا، إنتاج لقاحات ترخص محليًا بعلامة مصرية، سواء برخصة إنتاج من جهة خارجية أم عبر الترخيص للقاحات تنجزها فرق بحثية محلية. والملاحظ أن الإعلام الرسمي وشبه الرسمي قد كرر تصريحات لعدد من المسؤولين تفيد عمل فرق بحثية مصرية على عدة لقاحات. يبرز من بينهما لقاحان ترددت معلومات بشأن

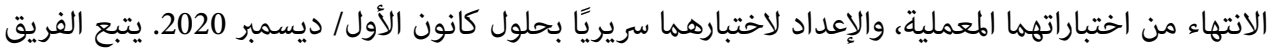

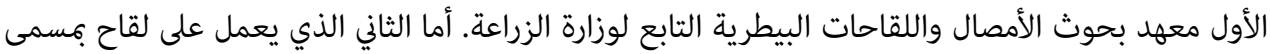

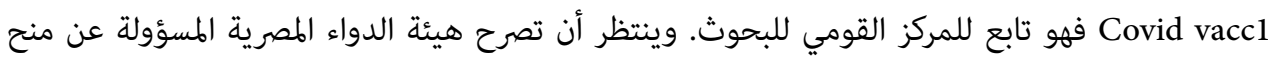
تراخيص الإنتاج والاستخدام حال انتهاء التجارب السريرية. وإذا ما نجح، يتوقع أن ينتج عبر مصانع هيئة المصل

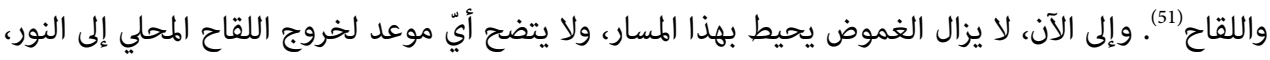
ومدى فاعليته (52).

أما فيما يخص توزيع اللقاح، فقد بقي الأمر يكتنفه الغموض؛ فحتى آخر كانون الثاني/ يناير، مل يتم عمليًا تطعيم

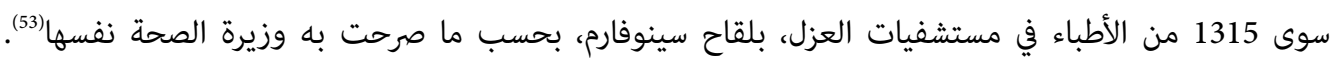
وفي حين أعلنت الحكومة عن سعيها إلى توفير 100 مليون جرعة من اللقاحات للمصريين، جاءت توقعات رئاسة الجمهورية بألّا تتوافر اللقاحات قبل صيف العام الحالي (2021) لتزيد الشكوك حول إمكانية تأمين كمٍّ معتبر من جن التطعيمات قبل ذروة الإصابة (54).

كانت هيئة الدواء المصرية قد عجلت بتراخيص طارئة لاستخدام لقاحات ثلاثة، هي اللقاح الصيني سينوفارم واللقاح

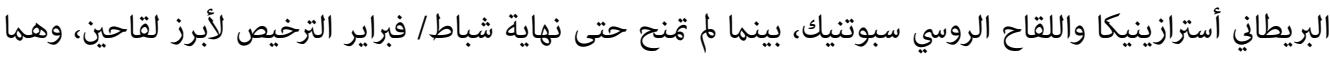
المنتجان من فايزر ومودرنا الأميركيين(55). وقد تضاربت الأرقام بشأن المتوافر فعليًا من اللقاحات؛ فعلى خلى خلاف لهاف تصريحات تؤكد أنه حتى الأسبوع الأخير من شباط/ فبراير كان إجمالي ما وصل إلى البلاد 400 ألف جرعة تتوزع مإن

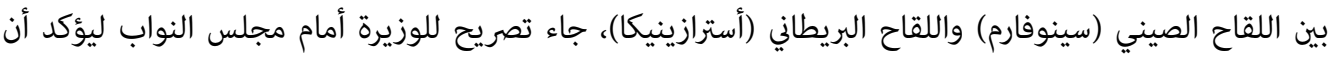

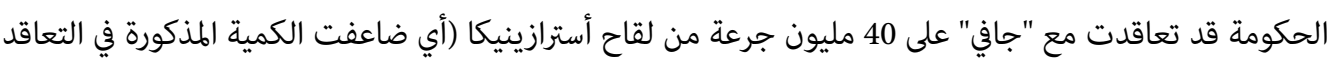

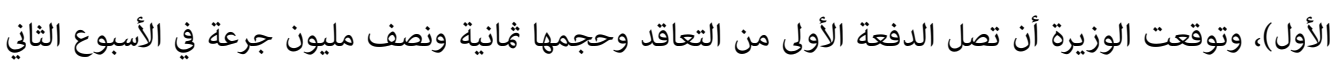

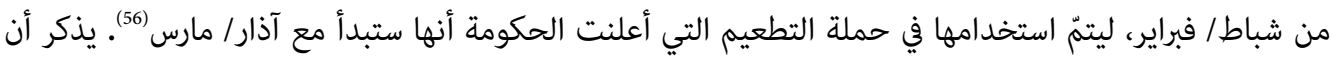
وزارة الصحة قد صرّحت بأن عملية التطعيم ستتولاها بمشاركة "صندوق تحيا مصر" والمؤسسة العسكرية ممثلة في هيئة الشراء الموحد وهيئة المستشفيات العسكرية.

https:/bit.ly/30vvdB1 51 "بشرى سارة.. لقاح كورونا المصري يصل مراحله النهائية"، البيان، 2020/11/23، شوهد في

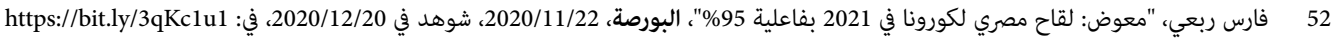

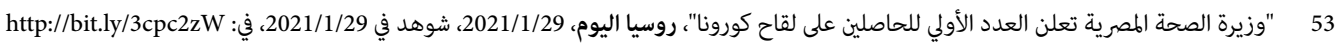
54 "كلمة السيد الرئيس إلى الشعب بشأن مواجهة فيروس كورونا"، قناة رئاسة الجمهورية على موقع يوتيوب، 2020/11/24، شوهد في https://bit.ly/30v2VGv

55 " 55 "مصر تعلن منح الترخيص الطارئ لاستخدام لقاح سينوفارم الصيني.. وموعد بدء التطعيم"، سي إن إن بالعربية، 2021/1/2، شوهد في 2021/2/25، https://cnn.it/2NGXQIp : فيح الرخاص 56 https:/bit.ly/3ck6UeP "محمد يوسف، "عاجل.. وزيرة الصحة تعلن التعاقد على 40 مليون جرعة لقاح جديدة"، الوطن، 2021/2/4، شوهد في 2021/2/10، في:/2X) 
كان لافتًا أنّ اللقاح الروسي سبوتنيك قد حظي بعقد توريد لعشرة ملايين جرعة، عبر شركة خاصة، بالرغم من أن

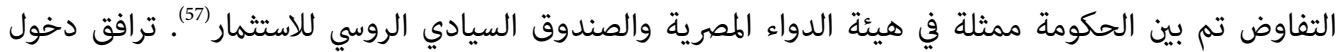

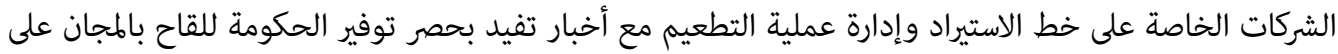

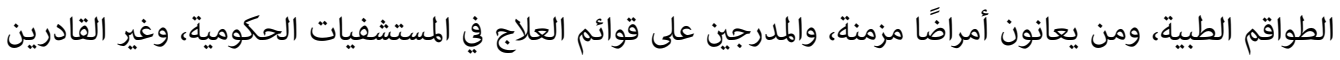

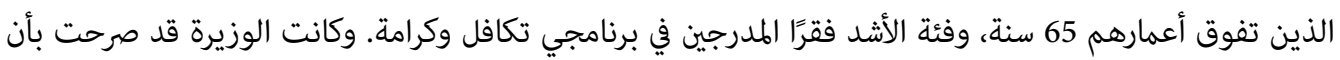
تكلفة التطعيم لغير هذه الفئات ستكون في حدود 200 جنيه مصري (58).

\section{2. التعافي الاقتصادي: تعزيز الأسواق والقدرات الإنتاجية مع خفض التكلفة}

\section{الاقتصادية على الفئات الهشة}

على الرغم من النقد الموجه إلى الحكومة بخصوص انحياز السياسات، فإنه يمكن ملاحظة علامات التعافي النسبي

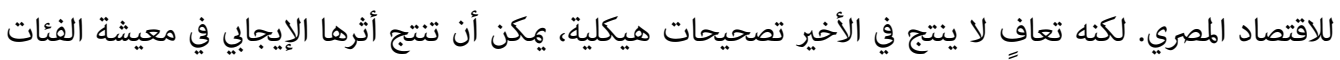
الاجتماعية الفقيرة والأشد تضررًا من الأزمة. وما هو متاح من بيانات عن مؤشرات التعافي يقصر أثرها على إبقاء الأزمة الاقتصادية عند حدود معينة، من دون تغيير حقيقي في المسار الاقتصادي ذي التوجهات النيوليبرالية. يكن تبين ذلك في الخطاب الحكومي الذي احتفى بالمنجزات على صعيد مالية الدولة، في حين تجاهل الوضع التنموي، بخاصة ما تعلق بمعيشة الفقراء. فقد ركز هذا الخطاب على مسائل من قبيل إيجابية تثبيت التصنيف الائتماني لمصر، وردد توقعات متفائلة للمؤسسات المالية الدولية، تفيد باستيعاب الاقتصاد المصري الأزمة، مع بدء مؤشرات تحسن فئن

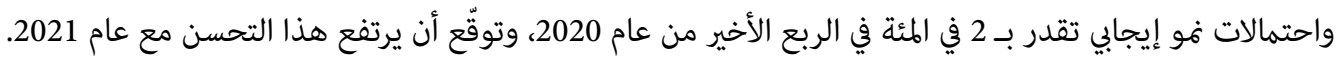

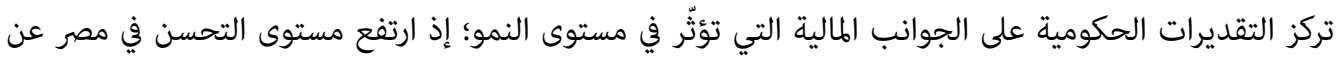

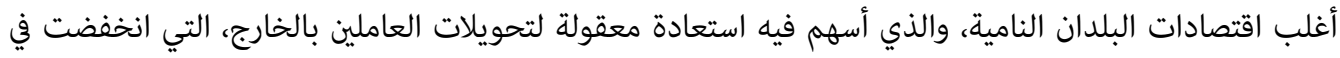
عام 2020 إلى مستوى قياسي، ومع عودة جزئية للنشاط السياحي في صيف العام المقبل (وهو الأشد تأثرًا بقرارات

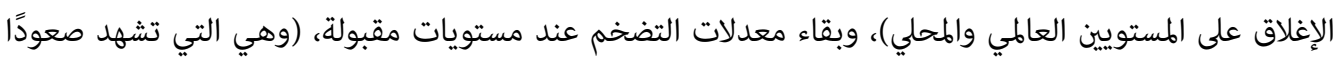

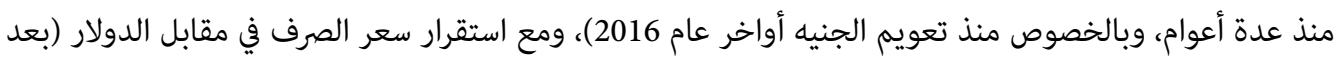

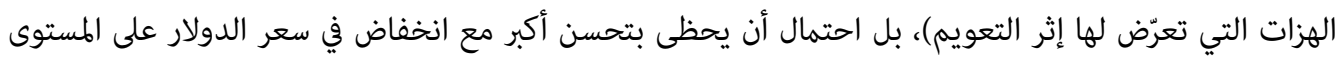

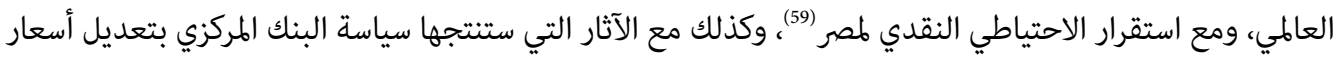

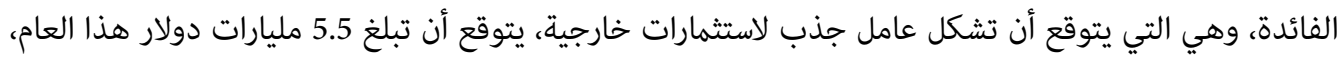

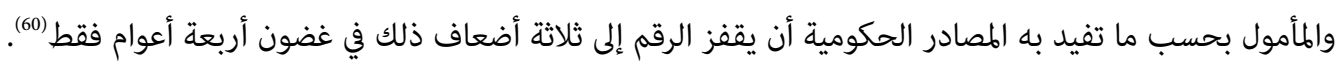

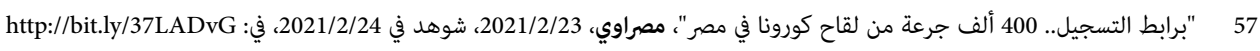

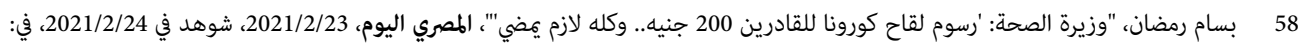
https://bit.ly/3cQCKQB

59 يتوقع صندوق النقد الدولي أن يبلغ الاحتياطي النقدي في مصر أربعين مليار دولار في نهاية العام المالي الحالي، وما يقل فقط خمسة مليارات عن

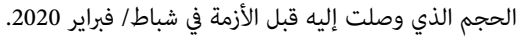

60 "Egypt's Economy Still Robust, Among Strongest in Emerging Markets: Goldman Sachs," Ahram online, 17/9/2020, accessed on 12/12/2020, at: http://bit.ly/3nI2ZwF 
لكن هذه التقديرات لا تأخذ في الحسبان عودة موجة ثانية من الجائحة على المستوى العالمي، في حين تعوّل على أثر

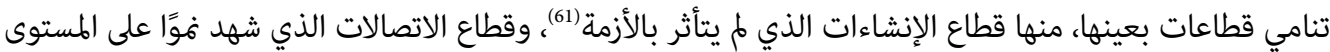
العالمي غير مسبوق بسبب الأزمة نفسها. لكن عودة القطاعات المصدّرة الصناعية والزراعية والخدمية إلى مستويات

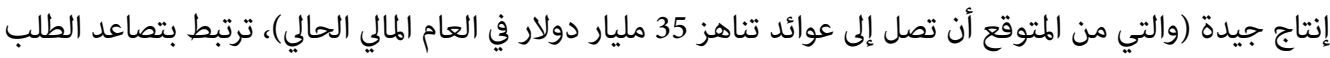

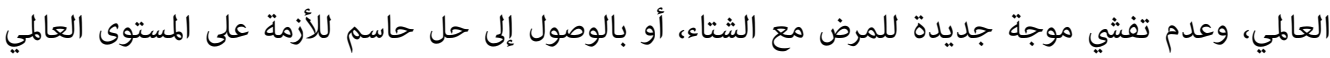

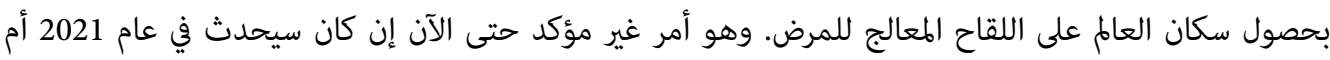

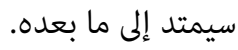

كذلك الحال بالنسبة إلى النشاط السياحي (وذروته في مصر هي موسم الشتاء)، فليست ثة مؤشرات حقيقية على

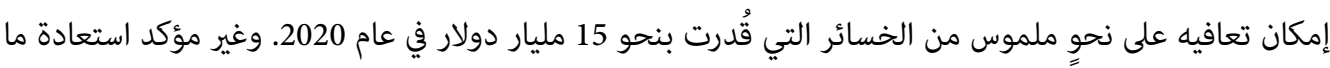

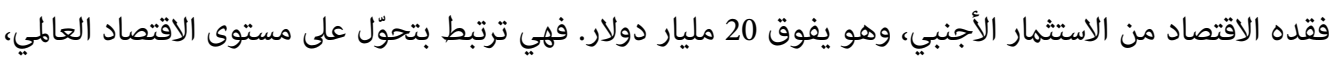

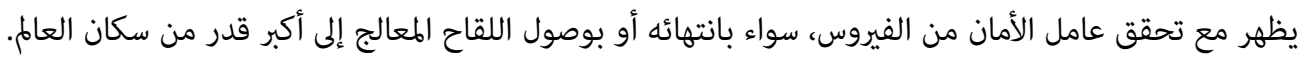
تتصل مسألة التعافي كذلك بتحقق أثر حزمة الإنقاذ في تعزيز قطاعات الإنتاج، خاصة منها ما يوجه للتصدير. لقد ركزت القرارات الاقتصادية على مساعدة القطاع الصناعي في خفض تكلفة الإنتاج، سواء بتخفيض بعض الته الالتزامات الضريبية أو عبر خفض أسعار الطاقة بعدما اشتكت الشركات منذ تعويم الجنيه في عام 2016 من صعوبة تحمّلها أسعار الطاقة. ويجادل البعض بأن قرارات خفض سعر الطاقة كانت مؤكدة؛ إذ صادفت اتجاه أسعار الطاقة على إنى المستوى العالمي نحو انخفاض جديد، فضلًا عن زيادة المعروض محليًا من الغاز الطبيعي. يبقى السؤال الأكثر تجاهلًا من جهة الحكومة متصلًا بسخائها الموجّه إلى الشركات على حساب المطلوب عاجلًا لإنقاذ الفئات الأفقر. ففي مقابل استمرار دعم الوقود للشركات، لا تزال سياسة رفع الدعم عن الوقود المخصص لاستهلاك

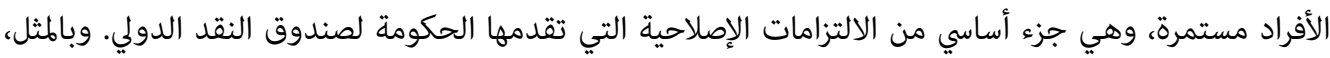
لا نجد السخاء الحكومي المتمثل في خفض الرسوم والتمغات (نوع من الرسوم) وخفض الضرائب على الشركات

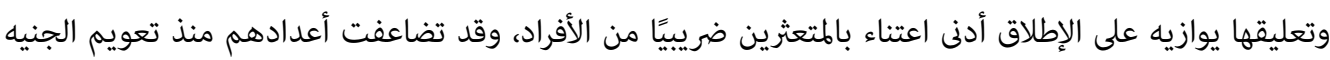

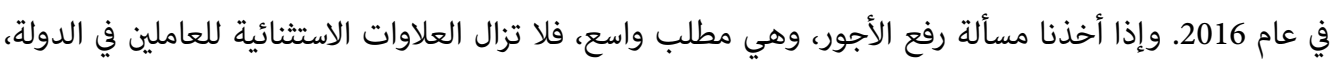
ومنهم العاملون في القطاع الصحي، ضعيفة. ليست محلًا للتساؤل بسبب ضآلتها فحسب، بل لأنها لم توضع بوصفي فئها علاوة دورية مستمرة، تستوعب أثر التضخم السلبي في الأجور. وليس أدل على مسلك الانحياز أكثر من تلك المنح

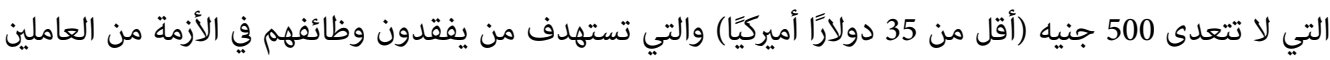
في القطاع غير الرسمي. فهل يمكن النظر إلى هذا المبلغ على أنه تعويض ذو شأن يعزز أوضاعهم المعيشية في مواجهة

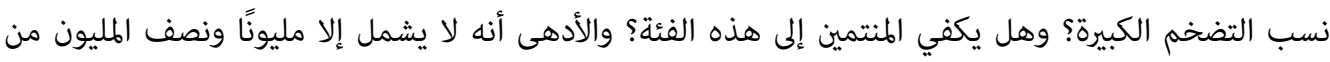

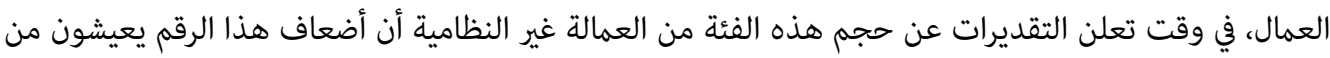
دون أي غطاء تأميني. 
لقد كان من المفترض في الحزمة المالية الضخمة أن تعزز الإنفاق الصحي الضعيف، لكن ذلك كان محدودًا جدًا، هذا على الرغم من التزامات الحكومة تجاه صندوق النقد الدولي لكي تحصل على تلك القروض التي يسّرها الصندوق

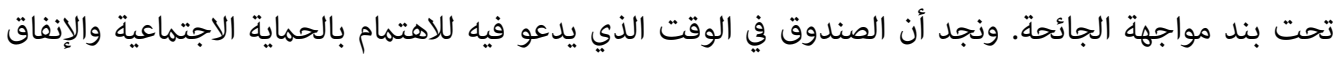

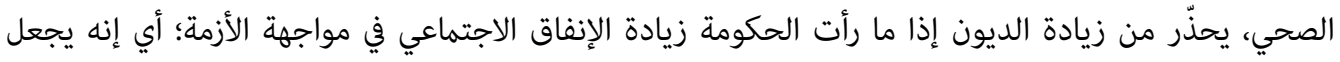

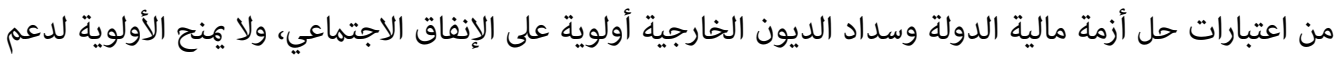

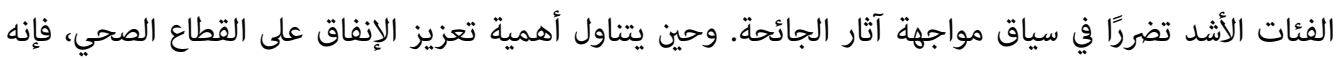
لا يرى موارد لذلك الإنفاق الاجتماعي مصدرًا من مالية الدولة المتاحة، وإفا يلح على "إيجاد إيرادات إضافية".

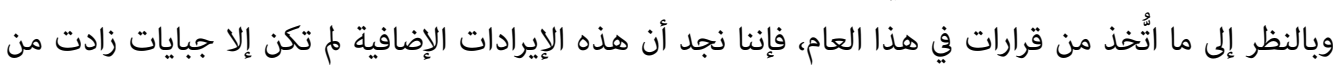

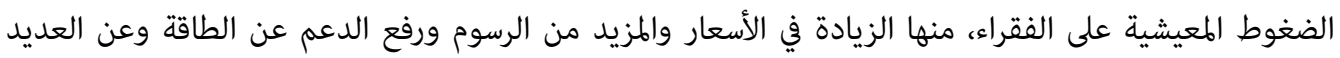
من السلع الأساسية.

\section{3. التعافي السياسي: الانفتاح السياسي مقدمة لاستعادة علاقات إيجابية بين}

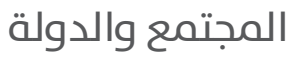

أظهرت الجائحة كيف أن علاقات الدولة والمجتمع لا تزال محكومة بقيود يمليها الأمن السياسي، وقد ضربنا أزمة

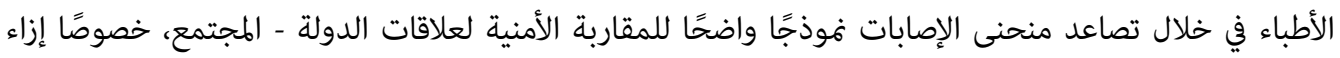
المجموعات الاجتماعية المنظمة. ثمة فموذج يمكن تبينه، إذ تعتمد السلطة مدخل استنزاف قدرات هذه المجموعات، بتوظيف أدوات القمع والاحتواء والتسكين، والمزج بينها لتحقيق أكبر قدر من الإنهاك.

صوّر الخطاب الحكومي أنّ نقد التدخل الأمني في القرار الصحي يناقض الدور المعتبر لقطاع الأمن في فرض إجراءات

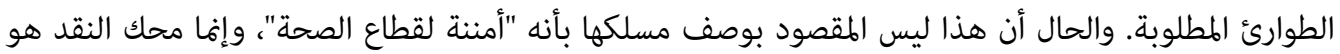

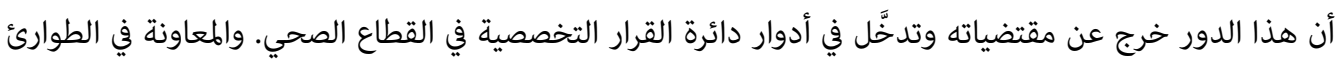

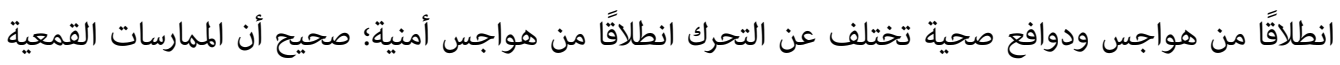

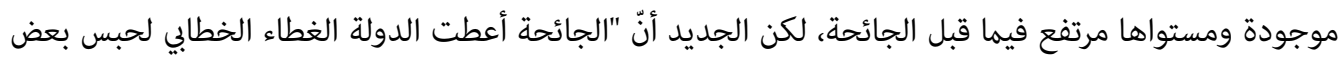

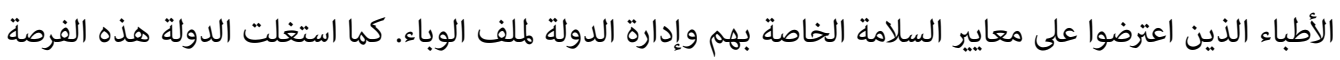

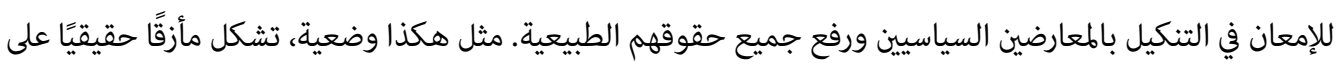
مستوى اللغة، وإشكالية كبيرة على مستوى طبيعة السيادة الهشة/ الغليظة للدولة المصرية"(62.)

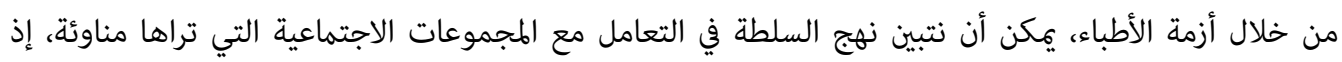

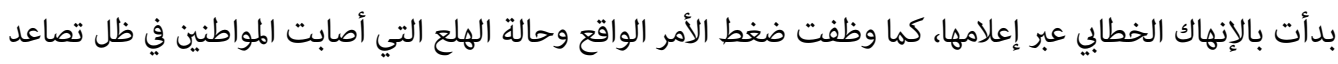
المخاوف من انفلات العدوى وتفشي الجائحة في تأليب المجتمع على الأطباء، وتم التعامل الإداري برسائل التهديد التها

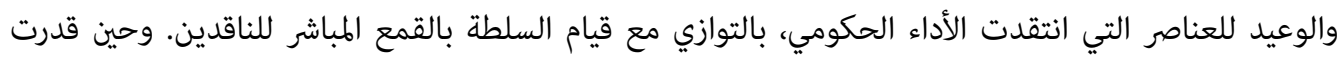

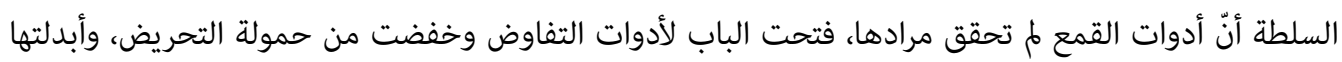


برسائل التقدير الرمزي (جيش مصر الأبيض، واعتبار المتوفين من الأطباء جراء الفيروس شهداء الوطن)، مع تقديم

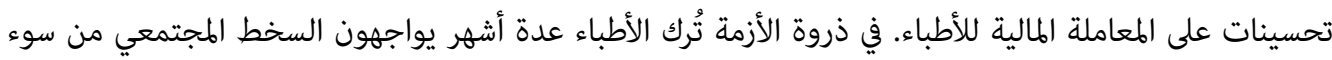

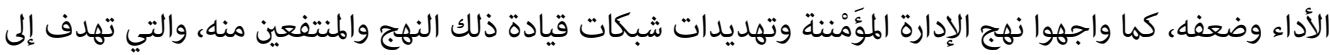
أن تضمن للسلطة ولاء الموظفين.

يجب تصحيح علاقات المجتمع والدولة لاستعادة الاستقرار، ومدخله فيما نزعم هو التحول النسبي عن المقاربة الأمنية ذات التوجه السياسي. لكن، إلى الآن، مل يحدث مثل هذا التحول مع ثبوت فداحة تكلفتهنه، فهو يأتي بنواتج عكسية، أشدّها حساسية أن يصبح النقد الخارجي هو ما يدفع النظام إلى تصحيح علاقة الدولة بالمجتمع، بينما

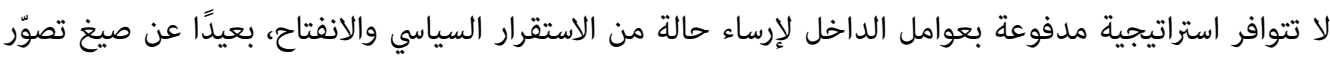

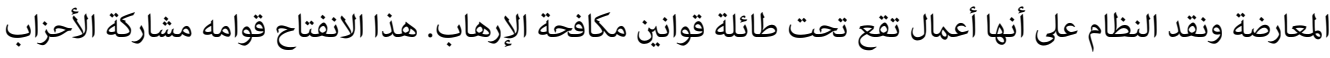
والمجموعات والروابط ومؤسسات المجتمع المدني في المواجهة، وإدارة علاقات متوازنة معها.

\section{خاتمة وتوصيات عامة}

أظهر هذا التقرير أن جائحة فيروس كورونا المستجد (كوفيد-19) مل تغير في الأوضاع المأزومة اقتصاديًا وسياسيًا في

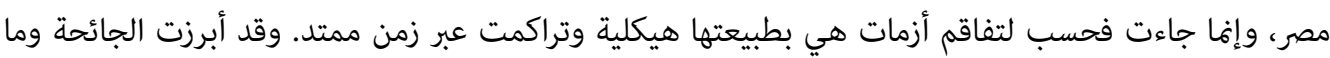

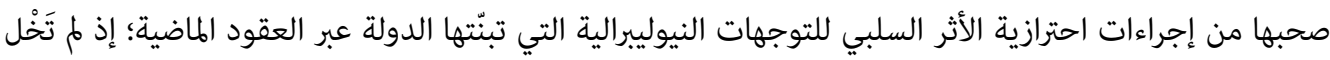
سياسات المواجهة من الانحياز الاجتماعي، وتسببت في تعريض الفئات الفقيرة والأشد هشاشة لآثار معيشية وخيمة. وأثبتت الجائحة أن رهن علاقات المجتمع والدولة باعتبارات الأمن السياسي يحذّ من قدرات المواجهة الاجتماعية للأزمات، هذا خلاف إضعافه كفاءة الحكم.

في العموم، وعلى الرغم من ترهل إجراءات التباعد الاجتماعي وضعف إدارة الوضع الوبائي، بدا عامل الديموغرافيا ذا

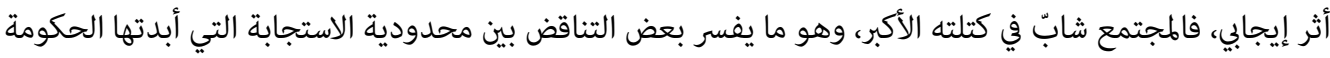
وما تعكسه الأرقام من انخفاض معاملات الإصابة والوفاة نسبة إلى عدد السكان. وفي الختام، نقدّم جملة من التوصيات من خلال ما رصده التقرير:

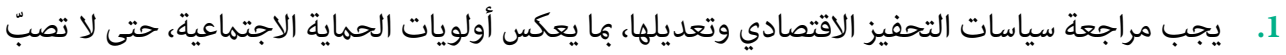

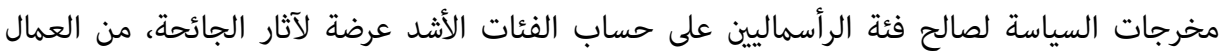

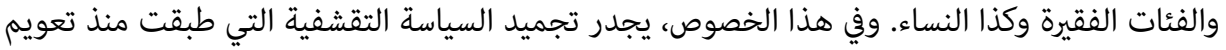
الجنيه في عام 2016، وعدم الانسياق وراء احتفاء صندوق النقد الدولي بتلك السياسة في زمن فن الجائحة؛

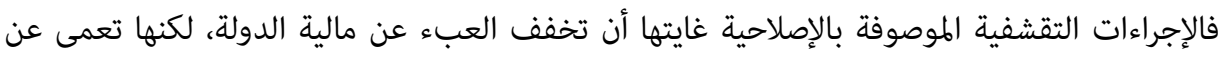

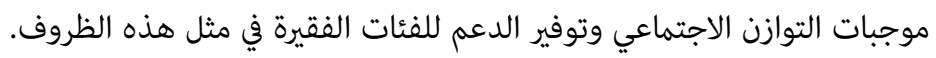
2. يظل تحرير الإعلام والسماح بكستوى حقيقي من الشفافية عاملًا مهمًا في تعزيز قدرة المجتمع على المواجهة.

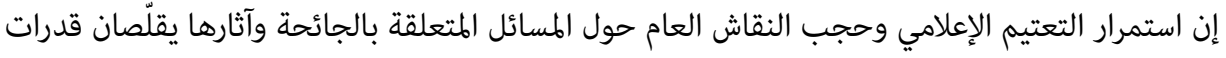

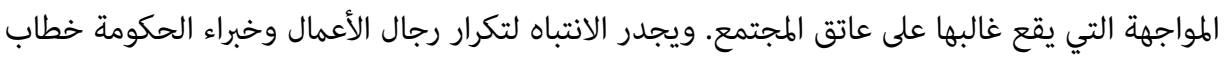


التخويف من الآثار الاقتصادية للجائحة، باسم "التوازن بين ضرورة الحفاظ على حياة المواطنين وبين

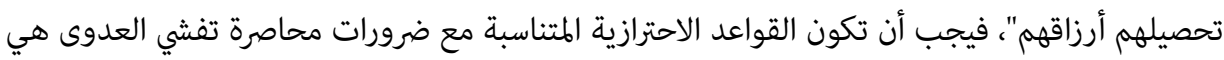
القيد الذي يقرر مدى استمرار النشاط الاقتصادي أو تقليصه، وليس مصالح أصحاب الأعمال. ضرورة فهم أنّ عدم الالتزام بالإجراءات الاحترازية لا يعكس فقط مستوى تردي الوعي الصحي لدى قطاع

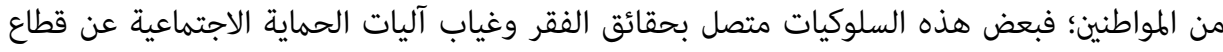

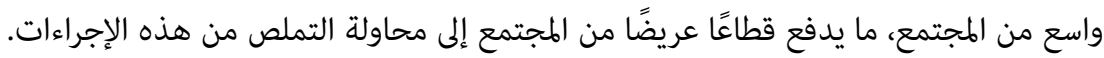
يجب على وزارة الصحة أن تتحلى بقدر أكبر من الشفافية عند التعامل مع مشكلات النظام الصحي، وألّا

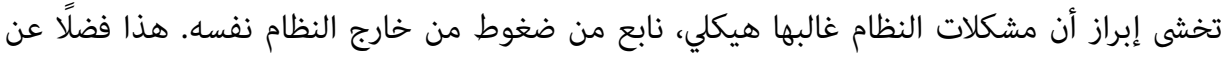
معوّقات سياسية تدفع بالقرار الصحي صوب حالة متطرفة من "تسييس المرض" لغايات أمنية أو بانحياز

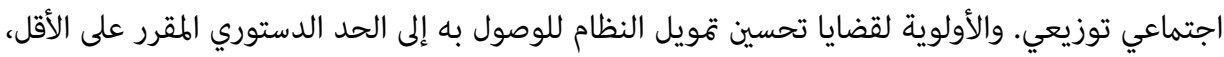
واستعادة عدالة توزيع الخدمة الصحية، والتأسيس لحوكمة جيدة في هذا القطاع، تعزز موقع العاملين فيه،

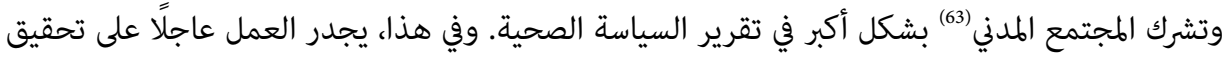

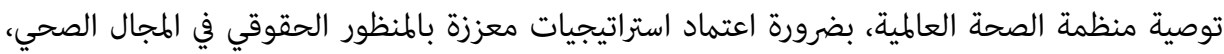
وتستهدف الحد من الفقر ونشر الخدمة على نحو متكافئ لجميع المواطنين (64). يجب العمل على علاج قصور البيانات الإحصائية والإكلينيكية الخاصة بوضعية الصحة في مصر، وإنشاء مراصد متخصصة، تبرز قضية الحرمان من الخدمة الطبية، وسبل مواجهتها. ويجب أن تستند سياسات الإصلاح إلى بحوث تأخذ في الحسبان احتياجات المواطنين وحقوقهم.

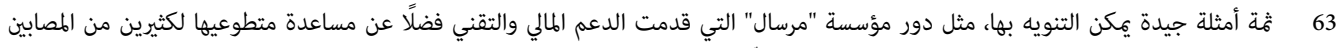

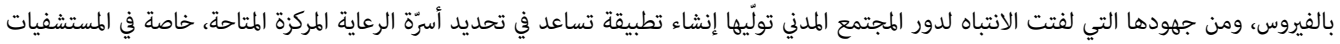

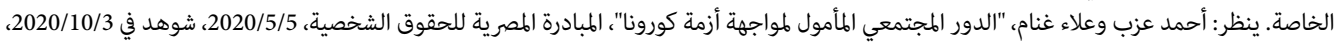
فttps://bit.ly/34FwTdv في آحمدة 
"استباحة الحياة الخاصة باسم القانون، قانون مكافحة جرائم المعلومات واستباحة خصوصية مستخدمي الاتصالات والإنترنت". تقارير. الشبكة العربية لمعلومات حقوق الإنسان. 2020/8/16. في: https://bit.ly/2Oy29WV "رغم التوقعات ببقاء الوباء .. خطط الحكومة لعام 2020 2021- خالية من الكورونا". ورقة موقف. المبادرة المصرية

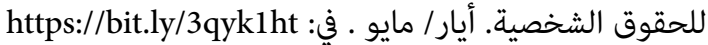
"معدل التضخم العام والأساسي". البنك المركزي المصري. كانون الثاني/ يناير 2021. في: https:/bit.ly/3eOH851 منظمة الصحة العالية/ المكتب الإقليمي لشرق المتوسط. حقوق الإنسان والصحة واستراتيجيات الحد من الفقر.

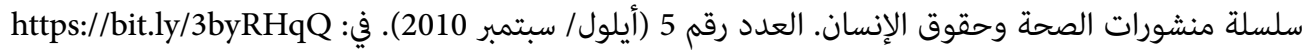

\section{الأجنبية}

"Egypt: Model Update." The Institute for Health Metrics and Evaluation. 29/10/2020. at: https://bit.ly/2OCfUUf

"New IHME COVID-19 Forecasts for Arab League Nations Find More than 50,000 Deaths in Egypt." The Institute for Health Metrics and Evaluation. 24/6/2020. at: https://bit.ly/3kZP1G2 "Policy Response to COvid-19." International Monetary Fund. at: https://bit.ly/3qvPW1R Sobotka, Tomáš et al. "Age, Gender and COVID-19 Infections," MedRxiv. 26/5/2020. at: https://bit.ly/3rv5KTY

Vollset, Stein Emil et al. "Fertility, Mortality, Migration, and Population Scenarios for 195 Countries and Territories from 2017 to 2100: A Forecasting Analysis for the Global Burden of Disease Study." The Lancet. vol. 396, no. 10258 (October 2020). at: https://bit.ly/3vlIJ8u 